Article

\title{
Earth-Observation-Based Estimation and Forecasting of Particulate Matter Impact on Solar Energy in Egypt
}

\author{
Panagiotis G. Kosmopoulos ${ }^{1, *}$, Stelios Kazadzis ${ }^{1,2}$, Hesham El-Askary ${ }^{3,4,5}$ (D), \\ Michael Taylor ${ }^{6}{ }^{\circ}$, Antonis Gkikas ${ }^{7}{ }^{\circ}$, Emmanouil Proestakis ${ }^{7}$, Charalampos Kontoes ${ }^{7}$ and \\ Mohamed Mostafa El-Khayat ${ }^{8}$ \\ 1 Institute for Environmental Research and Sustainable Development, National Observatory of \\ Athens (IERSD/NOA), 15236 Athens, Greece; stelios.kazadzis@pmodwrc.ch \\ 2 Physicalisch-Meteorologisches Observatorium Davos, World Radiation Center (PMOD/WRC), \\ CH-7260 Davos, Switzerland \\ 3 Center of Excellence in Earth Systems Modeling \& Observations, Chapman University, \\ Orange, CA 92866, USA; elaskary@chapman.edu \\ 4 Schmid College of Science and Technology, Chapman University, Orange, CA 92866, USA \\ 5 Department of Environmental Sciences, Faculty of Science, Alexandria University, Moharem Bek, \\ Alexandria 21522, Egypt \\ 6 Department of Meteorology, University of Reading, Reading RG6 6BB, UK; Michael Taylor \\ michael.taylor@reading.ac.uk \\ 7 Institute for Astronomy, Astrophysics, Space Applications and Remote Sensing, National Observatory of \\ Athens (IAASARS/NOA), 15236 Athens, Greece; agkikas@noa.gr (A.G.); proestakis@noa.gr (E.P.); \\ kontoes@noa.gr (C.K.) \\ 8 New and Renewable Energy Authority (NREA), Cairo 4544, Egypt; mohamed.elkhayat@yahoo.com \\ * Correspondence: pkosmo@meteo.noa.gr
}

Received: 24 October 2018; Accepted: 21 November 2018; Published: 23 November 2018

\begin{abstract}
This study estimates the impact of dust aerosols on surface solar radiation and solar energy in Egypt based on Earth Observation (EO) related techniques. For this purpose, we exploited the synergy of monthly mean and daily post processed satellite remote sensing observations from the MODerate resolution Imaging Spectroradiometer (MODIS), radiative transfer model (RTM) simulations utilizing machine learning, in conjunction with 1-day forecasts from the Copernicus Atmosphere Monitoring Service (CAMS). As cloudy conditions in this region are rare, aerosols in particular dust, are the most common sources of solar irradiance attenuation, causing performance issues in the photovoltaic (PV) and concentrated solar power (CSP) plant installations. The proposed EO-based methodology is based on the solar energy nowcasting system (SENSE) that quantifies the impact of aerosol and dust on solar energy potential by using the aerosol optical depth (AOD) in terms of climatological values and day-to-day monitoring and forecasting variability from MODIS and CAMS, respectively. The forecast accuracy was evaluated at various locations in Egypt with substantial PV and CSP capacity installed and found to be within $5-12 \%$ of that obtained from the satellite observations, highlighting the ability to use such modelling approaches for solar energy management and planning (M\&P). Particulate matter resulted in attenuation by up to $64-107 \mathrm{kWh} / \mathrm{m}^{2}$ for global horizontal irradiance (GHI) and $192-329 \mathrm{kWh} / \mathrm{m}^{2}$ for direct normal irradiance (DNI) annually. This energy reduction is climatologically distributed between $0.7 \%$ and $12.9 \%$ in GHI and $2.9 \%$ to $41 \%$ in DNI with the maximum values observed in spring following the frequent dust activity of Khamaseen. Under extreme dust conditions the AOD is able to exceed 3.5 resulting in daily energy losses of more than $4 \mathrm{kWh} / \mathrm{m}^{2}$ for a $10 \mathrm{MW}$ system. Such reductions are able to cause financial losses that exceed the daily revenue values. This work aims to show EO capabilities and techniques to be incorporated and utilized in solar energy studies and applications in sun-privileged locations with permanent aerosol sources such as Egypt.
\end{abstract}

Keywords: solar energy; aerosol impact; earth observation 


\section{Introduction}

The various observed and predicted changes in global climate stem from the short-sighted use of fossil fuels as an energy source. To mitigate climate change while permitting continued industrial development, it is necessary to make greater use of renewable energy sources as soon as possible [1]. To this direction, renewables currently account for more than $22 \%$ of total global electricity generation, of which last year more than $400 \mathrm{GW}(32.4 \%)$ were produced from solar energy [2]. Over the last 5 years (2013-2017), an estimated $15 \mathrm{Gt} \mathrm{CO}_{2}$ eq of emissions was avoided through renewables, compared to the emissions that would otherwise have occurred from fossil fuels-based power [3]. As a result, the exploitation of renewables is becoming a main requirement in order to meet the sustainable development goals (SDG), which were institutionalized by the United Nations [4], without decelerating economic growth and reducing welfare.

The above situation is most relevant in developing countries like Egypt, which have historically been reliant on fossil fuels for electricity and the market for renewable energy was underdeveloped, without clear business models and practices to make energy more reliable and more affordable for citizens. Nevertheless, given its geographical location, the most important potential source of renewable energy for Egypt is the Sun. A country with high average solar energy potential [5] and a massive land mass, well positioned to benefit from the continued growth in solar power generation [6]. In order to succeed in providing $22 \%$ of its energy supply by renewables before $2030[7,8]$. By the end of 2015, $70 \mathrm{MW}$ of solar power was already operational in Egypt, with 1.8 GW in project development [9], while almost $7,600 \mathrm{~km}^{2}$ of desert were allocated in 2014 for future renewable energy projects, with permits for land allocation already obtained by the New and Renewable Energy Authority (NREA). As cloudy conditions in Egypt are rare, aerosols, mainly dust aerosols, are the most common source of solar irradiance attenuation $[10,11]$, causing performance problems in the photovoltaic (PV) and concentrated solar power (CSP) plants. In various cases aerosol and dust are able to cause solar energy losses of the order of $80 \%$ and $50 \%$, respectively [12-16]. In particular, the main source of aerosols in Egypt is Saharan dust and more specifically the Khamassen dust storms, which is a fifty days phenomenon (Khamaseen in Arabic means "fifty"), frequent from mid/March through April [17-22]. Aerosols are also responsible for changes in the radiative forcing (RF) of the Earth-Atmosphere system through their interaction with solar radiation [23]. As defined by the recent World Meteorological Organization report on "Aerosol Measurements, Procedures and recommendations" [24], "Aerosol Optical Depth (AOD) is the most important aerosol parameter, in terms of climate sensitivity along with well mixed greenhouse gases, for determining the direct radiative effect and forcing".

At the same time, continuous monitoring of the impact of particulate matter on solar energy has become an important activity at many research and operational weather centres $[12,25]$ due to the growing interest from the solar energy industry. In brief, aerosols, reduce the energy generation potential of solar panels by absorbing and scattering light, reducing the strength of the direct beam (from which energy generation is most efficient). Electricity supplied to the grid must balance demand such that unexpected fluctuations in the power generated by the solar facility are costly since they require the use of rapid-response generators (e.g., natural gas). Being able to predict solar generation allows cheaper energy sources to be used. As a result, the need for improved EO-based estimation and forecasting services of AOD and solar energy potential is substantial in order to fulfil the increasing integration of solar systems into the electricity grid and load exchanges with direct impacts for the transmission and distribution system operators (TSO and DSO, respectively) and their coordination [26]. The lack of forecasts or inaccurate forecasts results in an inefficient operation of the electricity system and can even endanger the security of supply. The prediction of AOD in Numerical Weather Prediction (NWP) models faces a number of challenges owing to the complexity of atmospheric aerosol processes and their sensitivity to the underlying meteorological 
conditions [27-29]. At the moment, there are numerous aerosol monitoring satellite sensors and operational forecasting services which provide the AOD at a high spatial and temporal resolution, while accurate predictions of the irradiance received at individual PV (where GHI is needed) or CSP installations (where DNI applies) are able to be estimated by various solar energy nowcasting and forecasting methods and systems [30-35], which are able to use as input the aerosol information from the aforementioned sources.

Many recent papers have studied the impact of aerosols and dust on the GHI and DNI [15,36-38] and particularly in Egypt [39-42]. In this study we investigate the particulate matter impact on solar radiation and energy in the region of Egypt by analysing long-term and forecast data sets of AOD in conjunction with a state-of-the-art real-time RTM technique. This technique [34] was developed, used and applied within several EU-funded projects (e.g., Geo-Cradle; http://geocradle.eu/en/) as the so-called Solar Energy Nowcasting SystEm (SENSE). SENSE is based on the synergy of RTM simulations, machine learning and real-time atmospheric inputs from satellites and models. In order to estimate and forecast the aerosol and dust impact on the solar irradiances, we integrated MODIS observations in a daily and climatological basis or CAMS 1 day forecasts, which is a combination of NWP modelling and measuring approach $[43,44]$, to the SENSE. The analysis was performed by: (i) calculating a 16-year AOD climatology from MODIS and quantifying the corresponding impact on GHI and DNI, (ii) using the MODIS daily AOD observation values for the last 3 years (2015-2017) to evaluate the CAMS forecasts for the whole Egyptian domain and for specific locations with high solar energy exploitation potential and (iii) proposing and testing three energy M\&P techniques; the CAMS as an holistic approach, the MODIS persistence (PERS) based on the previous day values and the MODIS climatology (CLIM) by using the 16-year average values. Finally, we made a brief financial analysis for a hypothetical scenario of a $10 \mathrm{MW}$ system in order to quantify the impact of aerosol and dust presence on the energy production from PV and CSP systems and on the annual, monthly and daily revenues under climatological and extreme dust event conditions. Section 2 presents data, methods and techniques used. Section 3 describes the solar power and energy results including the financial analysis for the aforementioned scenarios and in Section 4 we present our conclusions on the proposed EO solutions.

\section{Data and Methodology}

\subsection{Data}

\subsubsection{Model Forecasts}

For aerosols, dust estimation and forecasting we used the CAMS 1-day total AOD and dust AOD forecasts at $550 \mathrm{~nm}$, which are based on the Monitoring Atmospheric Composition and Climate (MACC) reanalysis tool and its aerosol type classification identifier [45]. The CAMS data set includes modelling of aerosols and satellite AOD data assimilation from MODIS and other data sources for consistent bias correction purposes $[43,46]$. The modelling part uses the ECMWF physical parameterizations for aerosol interaction processes and follows the corresponding particulate matter treatment in the LOA/LMD-Z model [47,48]. As presented in Reference [34] the main uncertainty of SENSE is linked with the uncertainty of the model inputs. In this case with the aerosol related ones, most importantly AOD. Reported CAMS AOD forecast uncertainty ranges from -0.1 to 0.2 in terms of mean bias against Aeronet sun photometer data [49] in winter and summer months respectively. In addition to the results of [49] we have used the El Farafra Aeronet site in Egypt and we have compared 180 existing Level 2 days of AOD data for the 2015-2017 period, with the CAMS AOD data used in this study. We found a mean AOD bias of 0.107 showing a CAMS overestimation, with a correlation coefficient of 0.74 which is in a relative agreement with [46,49]. [46] report also that the spatial agreement of CAMS AOD compared to MODIS, is very good confirming the capture of dust outbreaks and their spatiotemporal evolution. 
Aerosol classification, in brief, is based on annual or monthly climatology derived from the emission database for global atmospheric research and the speciated particulate emission wizard as described by [50], especially for dust particles, is a combination of source functions [51,52], $10 \mathrm{~m}$ wind fields, land coverage, soil moisture and albedo in the ultraviolet-visible spectral region [53].

The CAMS AOD and dust AOD 1 day forecasts were obtained for the period from January 2015 to December 2017, at 3 hour time steps and 0.4 degree spatial resolution for the regions of Alexandria, Cairo, Suez, Hurghada, Aswan, Luxor, Marsamatrouh and Asyut as described in Table 1. NREA proposed these specific locations because of their appropriateness for the installation of solar farms that are able to cover the energy requirements of nearby residential areas and support the Egyptian electricity grid. Subsequently, this aerosol forecast information was the main input parameter, together with solar elevation, to the proposed RTM methodology for the determination of impacts on solar irradiances.

Table 1. Coordinates (degrees), population and average height (meters above sea level) of the specific locations in Egypt.

\begin{tabular}{cccccc}
\hline Location & Population & Code & Latitude & Longitude & Height (m.a.s.1.) \\
\hline Alexandria & $5,172,000$ & ALE & 31.2001 & 29.9187 & 12 \\
Cairo & $9,153,000$ & CAI & 30.0444 & 31.2357 & 75 \\
Suez & 744,000 & SUE & 29.9668 & 32.5498 & 5 \\
Hurghada & 288,000 & HUR & 27.2579 & 33.8116 & 14 \\
Aswan & 290,000 & ASW & 24.0889 & 32.8998 & 194 \\
Luxor & 507,000 & LUX & 25.6872 & 32.6396 & 76 \\
Marsamatrouh & 448,000 & MAR & 31.3543 & 27.2373 & 30 \\
Asyut & $4,123,000$ & ASY & 27.1783 & 31.1859 & 70 \\
\hline
\end{tabular}

\subsubsection{Satellite Observations}

MODIS, onboard the polar orbiting Aqua satellite, has provided cloud-free multi-wavelength aerosol retrievals, among other EO, since 2002. The primary aerosol product is the AOD, reported at $550 \mathrm{~nm}$, which is retrieved via the implementation of three individual algorithms operating separately over dark continental $[54,55]$ and maritime targets $[56,57]$ while thanks to the deployment of the enhanced Deep Blue (DB) algorithm [58], aerosol observations are possible over land areas characterized either by limited vegetation coverage, depending on the season, or by high surface albedo (i.e., deserts), excluding snow/ice covered regions [59]. These AOD retrievals, are merged providing almost full spatial coverage of the planet [60]. In the present study, MODIS-Aqua observations acquired from different collections (i.e., versions of the retrieval algorithm) and at different spatiotemporal resolutions (i.e., levels) have been utilized. More specifically, the Level 2 Collection 6 MODIS-Aqua AODs, over the period 2002-2017, as well as the corresponding L3 C061 datasets, over the period 2015-2017, have been processed. The former data are provided in 5 min intervals (i.e., swaths) and their spatial resolution is $10 \mathrm{~km} \times 10 \mathrm{~km}$ (nadir view) while the latter ones, aggregated to $1^{\circ} \times 1^{\circ}$ lat-lon grid, are available on a daily basis. The climatology of AOD in Egypt and its impact on solar energy potential was calculated in order to identify in monthly basis the attributes of the local and regional climatological conditions that favour the presence of aerosols from local emissions and/or long-range transport. Regarding the fine resolution of MODIS data, these have been regridded at an equal $0.1^{\circ} \times 0.1^{\circ}$ projection and then the monthly values, used as inputs to the RTM, have been calculated for the entire domain of Egypt. From the raw L2 and L3 files, both accessible at the Level-1 and Atmosphere Archive \& Distribution System Distributed Active Archive Centre (https: / /ladsweb.modaps.eosdis. nasa.gov/), the scientific data sets named as "AOD_550_Dark_Target_Deep_Blue_Combined" and "AOD_550_Dark_Target_Deep_Blue_Combined_Mean", respectively, have been extracted and analysed. There are four Quality Assurance (QA) flags (0: No Confidence, 1: Marginal Confidence, 2: Good Confidence and 3: Very Good Confidence) assigned to each MODIS L2 AOD retrieval indicating its "reliability." In the "merged" L2 AODs, the QA flags vary among the Dark Target (DT) 
$(\mathrm{QA} \geq 1$ over ocean and $\mathrm{QA}=3$ over land) and $\mathrm{DB}(\mathrm{QA} \geq 2)$ algorithms while the derivation of the $\mathrm{L} 3$ AODs is relied on spatial averages of L2 pixels weighted by their QA confidence level [61]. Finally, MODIS AOD uncertainty and validation are presented in References $[59,60,62]$ showing an agreement with Aeronet measurements in the regions of North Africa and Middle East. In particular, the bias of DB AOD product is -0.036 and the corresponding of DT is reduced to -0.013 [60].

\subsection{Methodology}

\subsubsection{Radiative Transfer Modelling Technique}

We used an existing technique, which is based on RTM simulations produced by libRadtran $[63,64]$, machine learning in the form of a continuous function-approximating model, or a Neural Network (NN) model and a variety of atmospheric inputs covering clear-sky and all-sky conditions. This technique is the so-called SENSE system and its technical background and validation were described in detail in Reference [34]. In brief, we first developed a large scale look-up-table (LUT) with more than 2.5 million RTM simulations by using the pseudo-Spherical Discrete Ordinate Radiative Transfer solver [65] and with input parameters the solar zenith angle (SZA), the AOD, the ice and water cloud optical thicknesses, the Angstrom exponent (AE), the single-scattering albedo (SSA), the total ozone column (TOC) and the columnar water vapor (WV) (Abbreviations presents the complete list of abbreviations). All the technical and structural information about the RTM simulations, the LUT construction and specific features are presented in Reference [66]. Then, a series of NNs were trained on solar irradiances spectra and on integrated irradiances to produce instantaneous results covering the wavelength region between 285 and $2700 \mathrm{~nm}$. For multivariate input-output data, feed-forward NNs with a minimum of one layer of "hidden" neurons have been shown to be a universal function approximation [67]. For our approach we connected the input-output vectors via two network layers-one containing the hidden neurons with tanh activation functions and another containing output neurons with linear activation functions $[66,68]$ as depicted in Figure 1. This configuration allows the continuous and nonlinear functional approximation that relates the output vector (e.g., surface solar radiation; SSR) with the input vector (e.g., combination of atmospheric parameters).

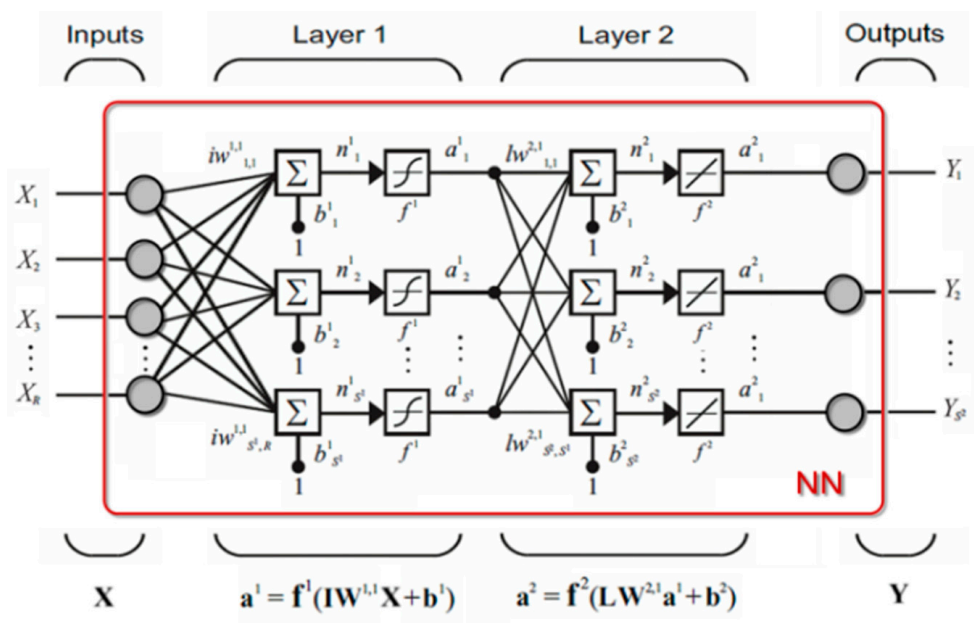

Figure 1. Schematic showing the NN architecture connecting the input and outputs parameters [66].

The above computing architectures, in conjunction with operational inputs from EO data sources like satellites and models, brought the "birth" of the SENSE system, which is capable of producing solar power and energy results in terms of GHI and DNI of the order of 1 million simulations in less than 1 minute in high spectral resolution $(1 \mathrm{~nm})$ depending spatially and temporally on the input parameter resolution (e.g., MODIS 0.1 degree and 1 day, CAMS 0.4 degree and 3 hours). SENSE was applied to various solar energy related applications through the EU-funded coordination and support action Geo-Cradle project by developing targeted and subsequent solar energy applications (http://solea.gr/). 
In this study, since cloudy conditions in Egypt are rare, we focused on the aerosols' quantification of impact on SSR by retrieving and exploiting the AOD from MODIS observations and the CAMS forecasts through the SENSE. In our RTM simulations we used the default aerosol model of [69] for ordinary particulate matter conditions (e.g., rural type aerosol in the boundary layer, background aerosol above $2 \mathrm{~km}$, spring-summer conditions and a visibility of $50 \mathrm{~km}$ ), which is the simplest way to include aerosols in libRadtran $[63,64]$. Since we specified the AOD impact on SSR, we simulated this parameterization by overwriting the default parameters with the integrated AOD using the aerosol_set_tau command [63]. More recent aerosol modelling efforts (e.g., the software package of Optical Properties of Aerosols and Clouds; OPAC [70]) are based on the aerosol component descriptions of [69], demonstrating the reliability and durability of the original aerosol model approaches. The parameterization was band-based [71] (correlated K-approximation) and for the gas absorption the molecular bands provided by Low-resolution atmospheric Transmittance and Radiance (LOWTRAN), while the code for spectral irradiance for the extra-terrestrial solar source spectrum was implemented.

Concerning other than AOD aerosol optical properties, water vapor and traces gases, that affect solar irradiance, input parameters were set to constant monthly climatological values from relevant data sources. In particular, the WV climatology was retrieved by the medium resolution imaging spectrometer onboard the European Space Agency's environmental satellite, the TOC from Ozone Monitoring Instrument (2008-2017) and the parameters SSA and AE were retrieved by the AeroCom database [72]. The impact of TOC on SSR is of the order of $0.5 \%$ for 100 Dobson unit differences, while for WV columns ranging between 0.5 and $2 \mathrm{~cm}$ the SSR difference is almost 3-5\% under low SZA (< 15 degrees) [34]. Regarding SSA and AE, we have used for both the constant value of 0.9 for the Egypt region. In order to assess the impact of the day-to-day variability of these properties on the SSR-related outputs and analysis, we have used their mean and standard deviation from the El Farafra Aeronet site for the period 2015-2017, which was found to be $0.91 \pm 0.02$ for SSA $440 \mathrm{~nm}$

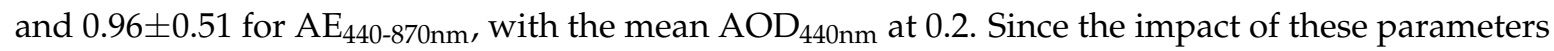
in the total solar irradiance is a function of AOD (and solar elevation) we have calculated the $\mathrm{k}=1$ uncertainties on the solar output based on the statistical standard deviations of the measured SSA and AE. Under climatological AOD levels, that is, 0.2 , the SSA uncertainty is \pm 0.22 for GHI and it is not affecting the DNI. The corresponding AE uncertainties were found to be \pm 0.5 and \pm 2.9 for GHI and DNI respectively. For a case of a dust episode (e.g., $\mathrm{AOD}_{440 \mathrm{~nm}}=0.8$ ) the uncertainties of $\mathrm{SSA}_{440 \mathrm{~nm}}$ increase to \pm 0.8 for GHI and for AE they are \pm 2.8 and \pm 11.4 respectively, pointing out that they become significant only for DNI and AE variability, while for all other cases is less than $4 \%$. These results are comparable with similar sensitivity analysis of radiative transfer studies $[66,73]$ considering overall these differences as a scale of error introduced by this approach.

The solar irradiance outputs were produced in terms of solar power (in $\mathrm{W} / \mathrm{m}^{2}$ ) and based on the time dimension provided by the CAMS and MODIS temporal resolution we calculated the corresponding daily, monthly and annual sum of solar energy (in $\mathrm{kWh} / \mathrm{m}^{2}$ ). The reliability of the RTM techniques of SENSE were tested against ground-based measurements from southern Africa to northern Europe [34] by comparing the simulated outputs with selected stations from the baseline solar radiation network as well as under high aerosol loads [15], while CAMS outputs are continuously validated through analytical reports [74].

\subsubsection{Energy Management and Planning (M\&P)}

Accurate solar energy forecasts are crucial in the energy exchange marketplace, where on-the-spot energy prices are defined by supply and demand equilibriums [2]. Simultaneously, knowledge of the solar energy potential of each location is a basic condition for solar farm investment for effective energy planning and determination of the break-even point, at which the total cost and total revenue are equal. Therefore, the energy M\&P requires interactive decision making solutions in order to forecast the input and output loads of the solar facilities. Based on the combination of SENSE with the CAMS aerosol input, we propose this synergy as a robust approach that provides operationally aerosol and dust 
impact on solar energy. Additionally, we test other EO-based solutions which use as aerosol input information to SENSE the MODIS observations by the following ways: (i) by exploiting the previous day of observations and apply them to the current day as persistent (PERS) aerosol conditions, forming a forecasting technique that from hereafter we will call MODIS PERS and (ii) by calculating the MODIS AOD climatology (CLIM) and use monthly averages, an approximation method that we will call MODIS CLIM. The utility behind these two approaches has to do with the ease of application but with consequential uncertainties, especial under unusually high aerosol loads (e.g., dust events). Figure 2 depicts the procedural flows, starting from the two aerosol data sources (CAMS and MODIS), converting the AOD values to solar irradiances (GHI and DNI) through the SENSE and the corresponding solar energy forecasting outputs. SENSE-CAMS solution is operational-ready with continuous provision of modelled AOD inputs, while SENSE-MODIS solution is the observational AOD solutions but under deferred and homogenized aerosol actual conditions. This modelling scheme is able to act as an holistic approach for energy M\&P in sun-privileged locations like Egypt with dominant particulate matter sources.

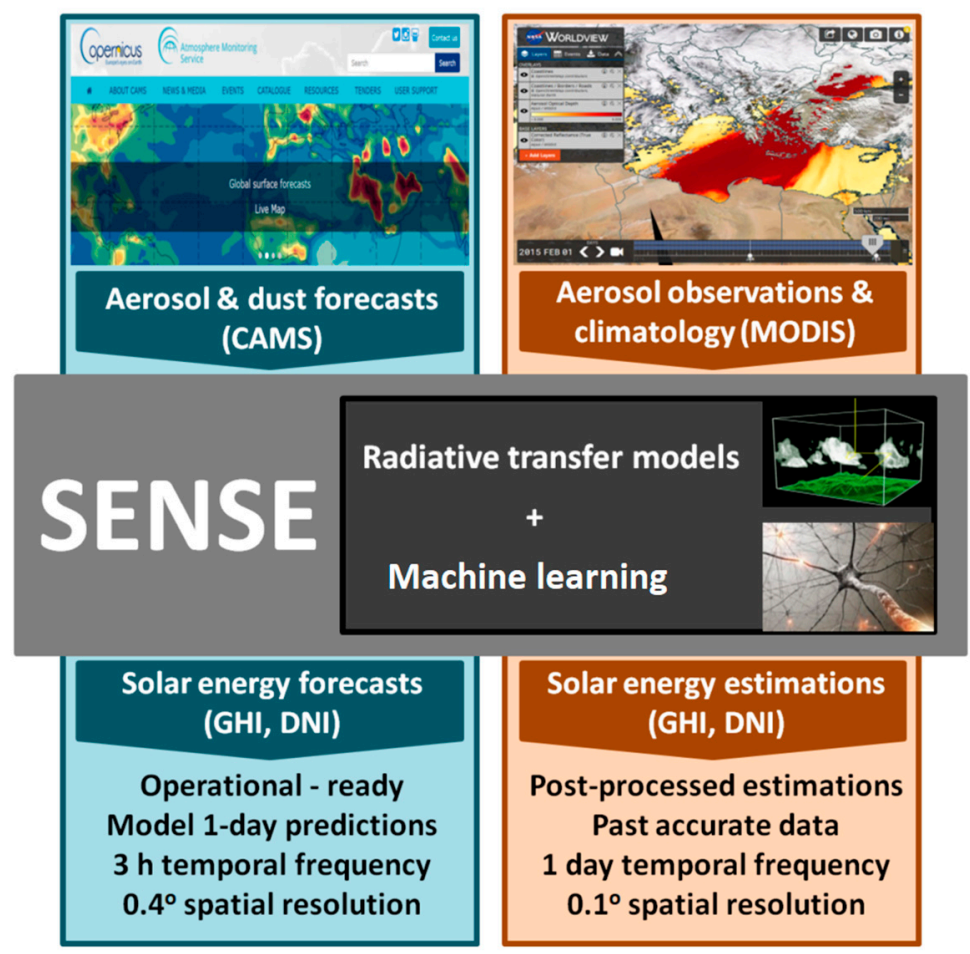

Figure 2. Flowchart of the SENSE scheme. The initial data sources followed by the observational or forecasted aerosol inputs to the SENSE and the analogue solar energy related outputs.

\subsubsection{Financial Analysis}

For the financial analysis we simulated a hypothetical scenario of a PV and a CSP system with nominal power of $10 \mathrm{MW}$ assumed to be installed in Cairo, Asyut and Aswan. Figure 3 presents all the studied locations, including CAI, ASY and ASW, located along the river Nile and we will describe the financial analysis in Section 3.4. These locations were selected because of their different latitudes to represent conditions with various aerosol sources and solar energy potential levels. The system specifications were classified into the exploitation of GHI from PV technologies and DNI from CSP plants. The annual energy production results were cross validated with existing solar farms in Morocco, California and South Africa. Particularly, in Morocco the Noor 1 CSP (160 MW) produces almost $370 \mathrm{GWh}$ on an annual basis, while in California, a CSP of nominal power $392 \mathrm{MW}$ gives back annually 1,079 GWh. In South Africa, from a 100 MW CSP they exploit 480 GWh and from 96 MW and 75 MW PVs they take back energy output of about 180 and 150 GWh respectively. 
Bringing the above solar farm projects into the solar energy potential levels of the selected locations in Egypt we found the corresponding energy outputs [8], which reflect the local latitudinal conditions. As a result, a $10 \mathrm{MW}$ system in the region of Egypt is able to produce annually almost 25,687 MWh by using a required area of 130,000-150,000 $\mathrm{m}^{2}$ for PV (depends on the material used, for example, crystalline silicon, cadmium telluride) and 280,000-360,000 $\mathrm{m}^{2}$ for CSP installation (depends on the technology used, for example parabolic trough, solar tower).

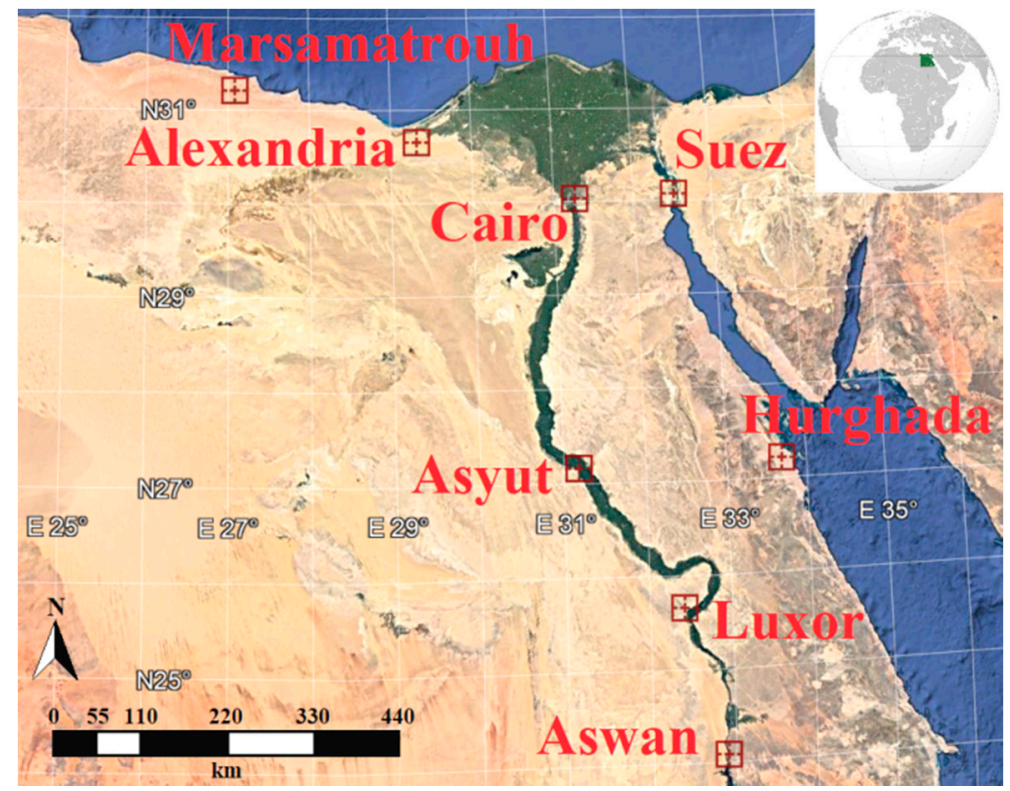

Figure 3. Study region and the specific locations of ALE, CAI, SUE, HUR, ASW, LUX, MAR and ASY. In CAI, ASY and ASW a financial analysis was additionally performed.

Concerning the system and calculation assumptions, for the PV calculations, a realistic efficiency value of $12 \%$ has been used alongside a spatial coverage of $80 \%$ and material combined losses of $29 \%$ for the most common material used, which is the crystalline silicon [75]. For the CSP, the energy storage facilities have been considered, for a required capacity of 14 hours which ensures full self-sufficiency, as well as its heat losses, the losses by shading, incidence angle modifier, the end losses and the peak optical efficiency [76,77]. For the hypothetical system scenario and its nominal power, the actual system power performance in MW has been used instead of MWp, where the peak power rating on a solar system represents the most power that it would produce under ideal conditions for solar production. For the calculation of the provided financial analysis results, the associated revenue is straightforward; one needs to multiply the produced energy by the price (USD/kWh) applicable to this hypothetical $10 \mathrm{MW}$ system scenario. NREA proposed a realistic selling-electricity-to-the-grid price value (feed-in tariff) of $0.0382 \mathrm{USD} / \mathrm{kWh}$ [6]. As real new projects are procured or launched globally and the "feed-in" prices are reduced in correlation to reduced investment and operation costs (for both CSP and PV projects), prices like the used in this study might be also reduced by the time a project kicks-off. As a result, this price should be seen as an assumption that should be further substantiated in direct contact with the Egyptian Authorities. Another assumption is the maintenance of the PV and CSP plants including the solar panels cleaning after for example dust deposition [13]. Finally, the presented financial analysis was expressed in terms of Energy Production (EP), Daily Revenue (DR) and Financial Losses (FL). EP is the sum of the generated energy in $\mathrm{kWh} / \mathrm{m}^{2}$. DR is the EP multiplied by the feed-in tariff price. FL are described by the equation $\mathrm{FL}=\left(\mathrm{EP}_{\text {possible }}-\mathrm{EP}_{\text {actual }}\right)$ * price, where $\mathrm{EP}_{\text {possible }}$ is the possible $\mathrm{EP}$ under aerosol-free conditions and $\mathrm{EP}_{\text {actual }}$ is the actual EP taking into account the particulate matter impact. 


\section{Results and Discussion}

\subsection{Climatological Impact}

Figure 4a shows the 16-year climatology of AOD from MODIS for the greater Egypt region. It is a combination of the MODIS algorithms DT and DB Level 2 which provides reliable aerosol optical properties for arid regions like Egypt at high spatial resolution (0.1 degree). The AOD at $550 \mathrm{~nm}$ was found to range from 0.034 to 0.966 indicating the strong particulate matter background of the region especially in spring and summer months. Summer was found to present high aerosol loads $[10,16,22]$ mainly because particle accumulation is favoured in this season by the absence of precipitations and by atmospheric stability [78]. On the other hand, the highest values (>0.8) are in April when particles produced by natural processes like the wind-erosion of desert surfaces and in particular the Khamaseen dust storms [17-22]. The Nile Delta was depicted also from February to October with large AOD values caused by burning activities of local agricultural wastes $[19,78]$, while other highlighted locations like the Red Sea and the central parts of Egypt are a combination of aerosol sources as other studies found [22].
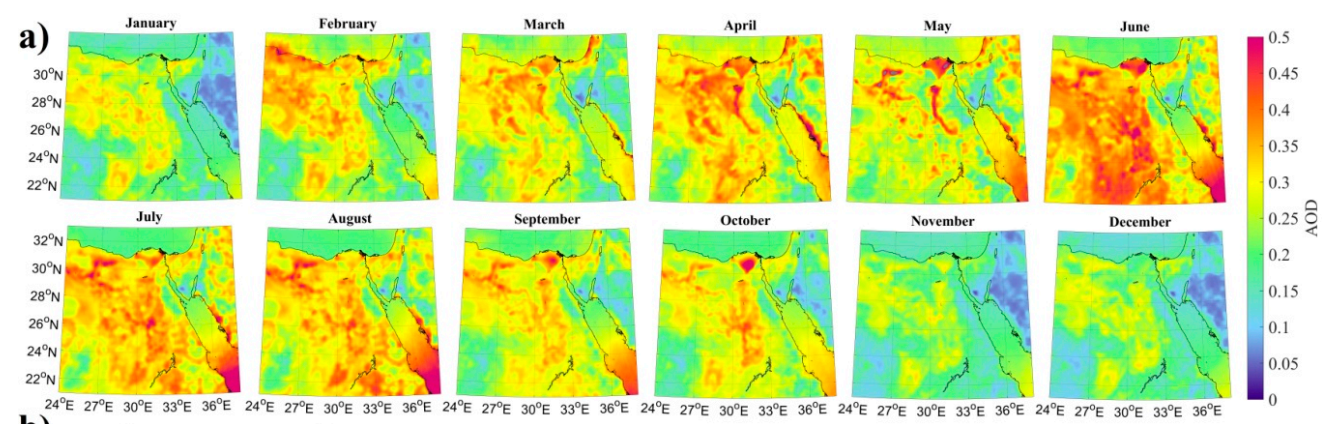

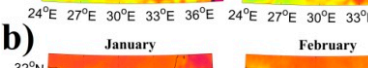
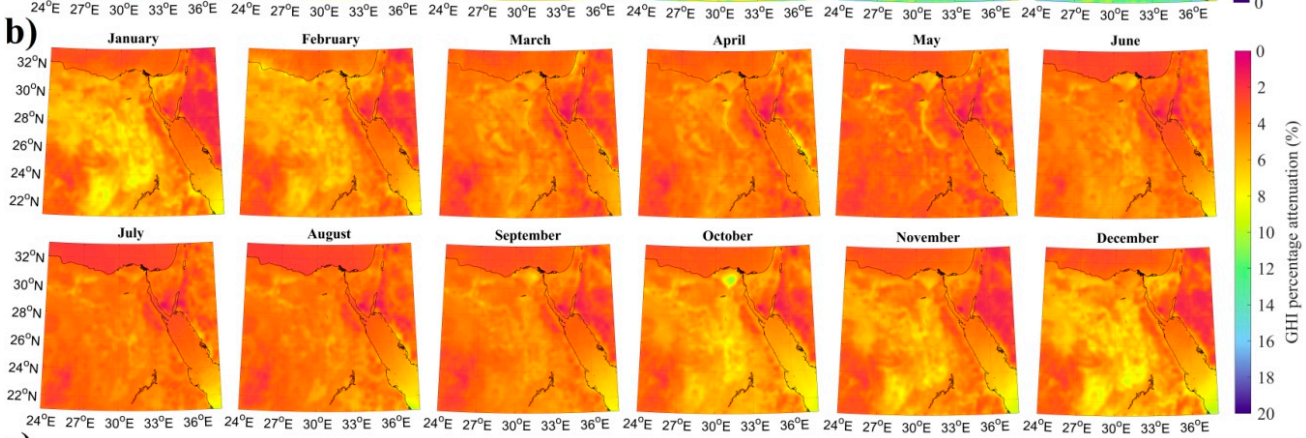

c)
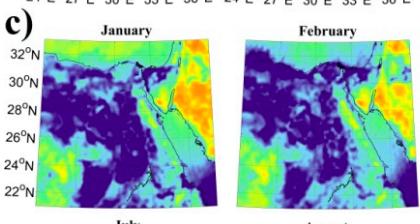

March
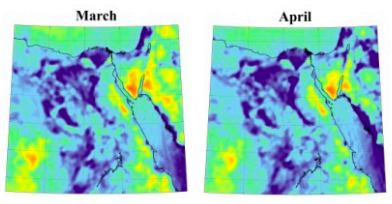

April
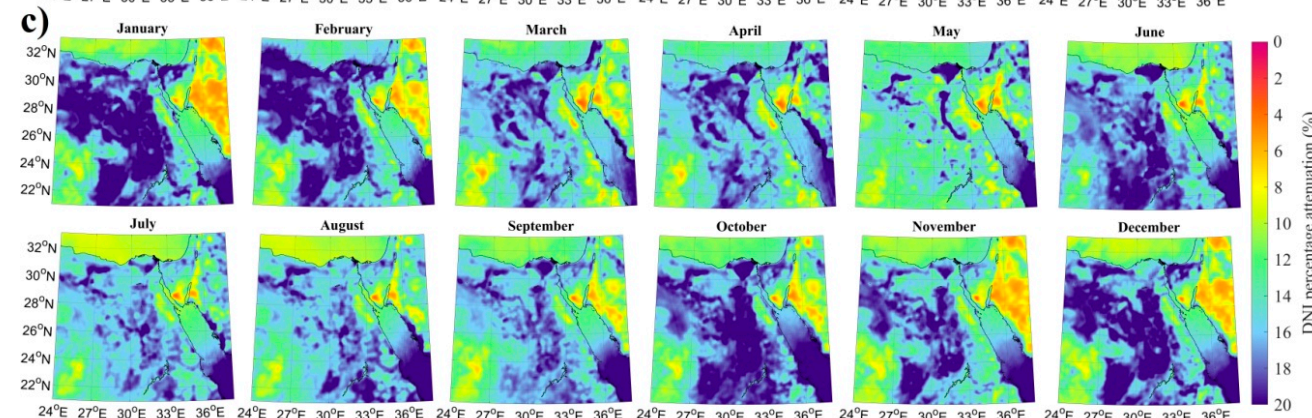

Figure 4. Monthly averages of (a) AOD at $550 \mathrm{~nm}$ in Egypt using the DT and DB Combined Level 2 product of MODIS for the period 2002-2017, (b) GHI and (c) DNI solar energy percentage attenuations relative to the aerosol-free simulations under MODIS-based AODs.

These aerosol patterns denatured into GHI and DNI percentage attenuations in Figure $4 \mathrm{~b}, \mathrm{c}$, respectively. The percentage attenuations were calculated by the RTM calculations using as aerosol input the AOD and were compared to clean and clear sky conditions with the aerosols set to zero value, while the simulated time for both MODIS aerosol and aerosol-free conditions was at local noon. 
For the RTM calculations the SENSE was used which produced almost 1.5 million simulations for the implementation of these results. The range of GHI attenuation was found to be 0.7 to $12.9 \%$ while for the DNI component the corresponding attenuation values range from $2.9 \%$ to $41.0 \%$ highlighting the months and regions with the highest AOD climatological conditions as well as the fact that the majority of Egypt presents attenuation values larger than 15-20\%. These results are comparable with similar approaches [13] and indicate that the most important irradiance attenuation in the region is the particulate matter $[10,11]$. The corresponding impact from clouds is minimal reaching values of $2.8 \%$ under the annual period [79].

\subsection{Performance of CAMS}

Figure 5 describes the correlation of the CAMS forecasted AOD with the MODIS AOD observations (a), as well as the corresponding surface solar radiation levels (b) by using as inputs to SENSE the CAMS 1 day forecasts and the MODIS daily AOD observation values. We note that the comparison was performed for the locations of ALE, CAI, SUE, HUR, ASW, LUX, MAR and ASY for the past 3 years (2015-2017) during the MODIS overpass time positions. The coefficient of determination $(\mathrm{R})$ for the AOD data sources is 0.521 , while for the corresponding irradiance levels this correlation measure is significantly improved reaching $R=0.998$. This means that the observed AOD differences between CAMS and MODIS present minor affectability on SSR, with the spread increasing at higher SSR levels [12]. Such data behaviour shows that the AOD absolute differences in Egypt with standard deviation (SD) of 0.137 results absolute differences in solar radiation less than $1 \%$ under low radiation levels $\left(\mathrm{SD}=11.72 \mathrm{~W} / \mathrm{m}^{2}\right)$ as discussed in various similar comparison approaches $[15,46,74]$.
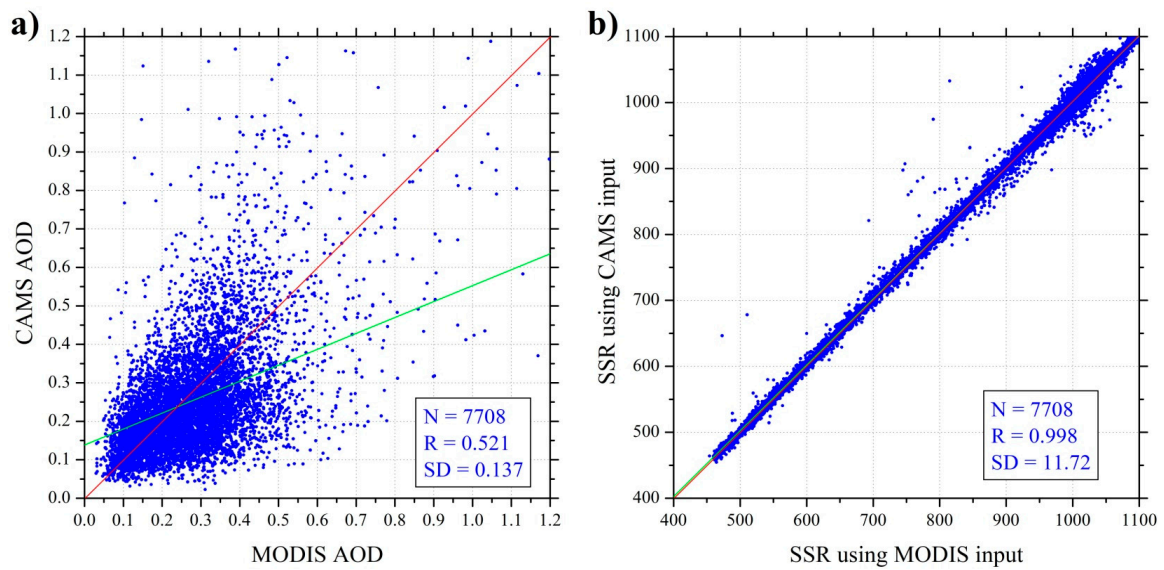

Figure 5. Scatterplots of (a) the CAMS forecasted AOD as compared to the MODIS observed values and (b) the SENSE simulated surface solar radiation (SSR) using as input the CAMS forecasted AOD as compared to the SENSE SSR using as input the MODIS AOD in Egypt for the period 2015-2017.

A more analytical description of the CAMS performance against MODIS observations is depicted in Figure 6. The CAMS AOD was plotted for a week with the MODIS daily and climatological values for the region of Aswan (a) as well as the simulated GHI (b) and DNI (c). The higher frequency of data from CAMS (1 per 3 hours) provides a more detailed monitoring of AOD and solar irradiances, while the differences from using MODIS AOD and CAMS inputs to SENSE are lower than $50 \mathrm{~W} / \mathrm{m}^{2}$ for GHI but are able to reach $150 \mathrm{~W} / \mathrm{m}^{2}$ for DNI. We note that the use of MODIS daily and climatological AOD encompasses the assumption of persistent aerosol conditions for the daily (MODIS daily value) and monthly (MODIS climatological value) time period performed. Furthermore, the comparison of the CAMS forecasts against the MODIS's 'truth' representation (real satellite observations), shows that the AOD differences presented in (a), have a minor impact on GHI, while on DNI highlight a known underestimation of CAMS under higher aerosol loads [15,46,74]. 

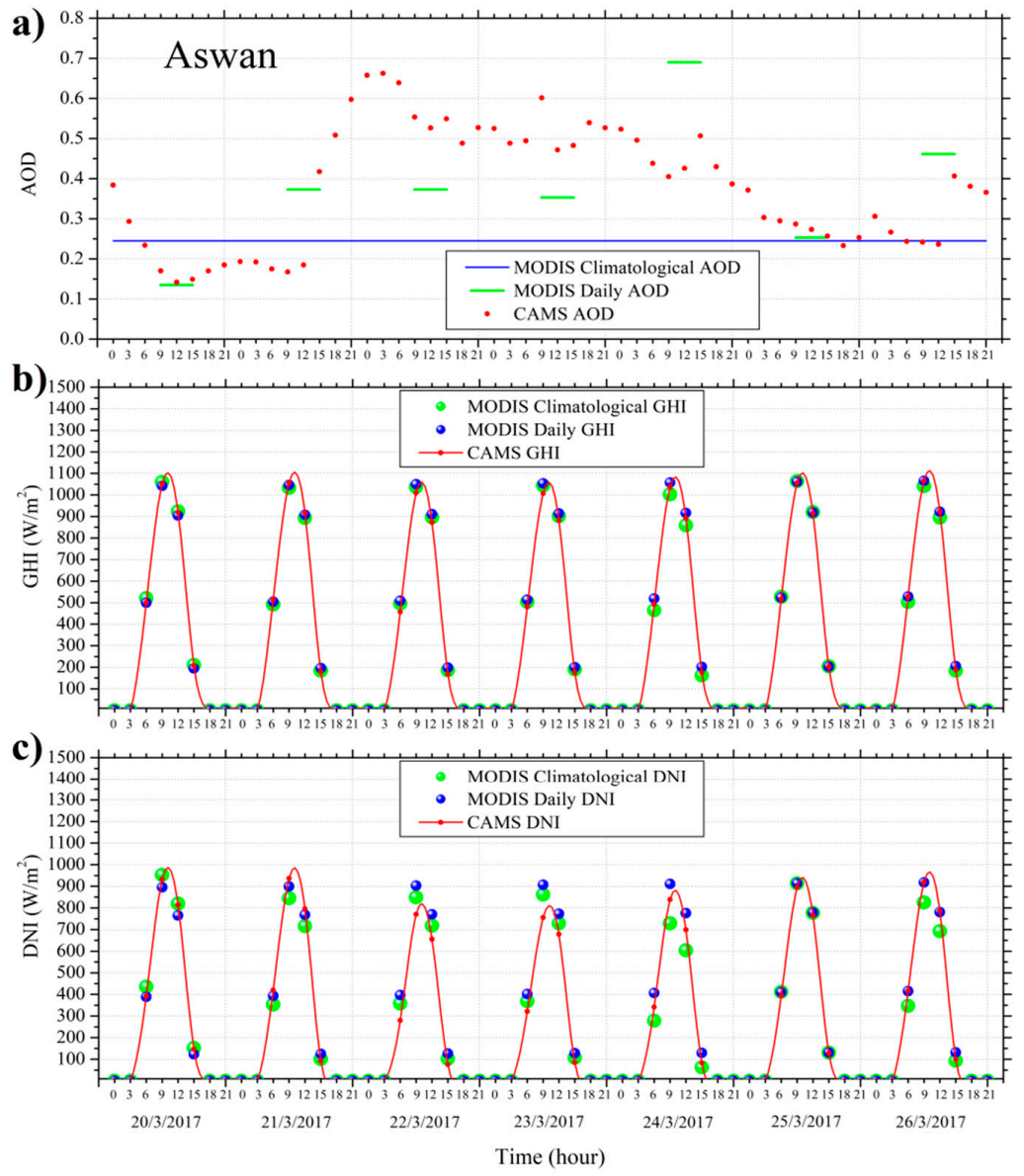

Figure 6. The AOD from MODIS climatology, MODIS daily observations and CAMS forecasts for a week period (20-26 March 2017) in Aswan (a) and the simulated by SENSE GHI (b) and DNI (c) using as inputs the SZA and the aforementioned AOD sources collocated to the CAMS temporal resolution of 3 hours.

\subsection{Performance of MEP Techniques}

The main scope for this comparison of M\&P techniques performance is to highlight the impact of the different temporal resolutions between CAMS forecasts and MODIS observations (1 per day for MODIS PERS and 1 per month for MODIS CLIM). The MODIS CLIM is able to provide information about the aerosol background for each location but is unable to monitor the intraday aerosol variability. The MODIS PERS makes the assumption that the AOD is persistent from the previous day's observation. This is useful for accurate aerosol levels but does not account for upcoming dust events or other spontaneous aerosol events. The CAMS 1-day forecasts provides information about the total aerosol and the dust particle levels based on the MACC classification as described in the previous Section 2.1.1. In any case this comparison between the forecasting techniques is able to provide useful information to the energy managing authorities and investors about the current potential EO solutions and to consider the opportunity cost from each aerosol, dust and energy forecasting approach.

Figure 7 depicts the monthly 3-year average (2015-2017) forecasting behaviour of CAMS, MODIS PERS and MODIS CLIM approaches as absolute energy losses for GHI and DNI (in $\mathrm{kWh} / \mathrm{m}^{2}$ ) for the eight locations in Egypt. In general, the greatest losses are during the spring and summer months, while the average losses of GHI range from 5 to $24 \mathrm{kWh} / \mathrm{m}^{2}$ and for DNI reaches $72 \mathrm{kWh} / \mathrm{m}^{2}$. By comparing the CLIM technique with the CAMS we found an overestimation in summer months at ALE and MAR locations and an underestimation at LUX [80]. ASW and ASY are being affected by continuous periods of dust transport and we highlight the high mean losses in ASW and the remarkably 
good agreement for the CAMS and PERS techniques in ASY in April, where Khamaseen dust storms are frequent in this month, showing that under such persistently high particulate matter levels the variability is lower, marking prediction easier. Overall, good agreement of CAMS and PERS is presented in all locations except CAI because of the complexity of the multi-source aerosol conditions [79].
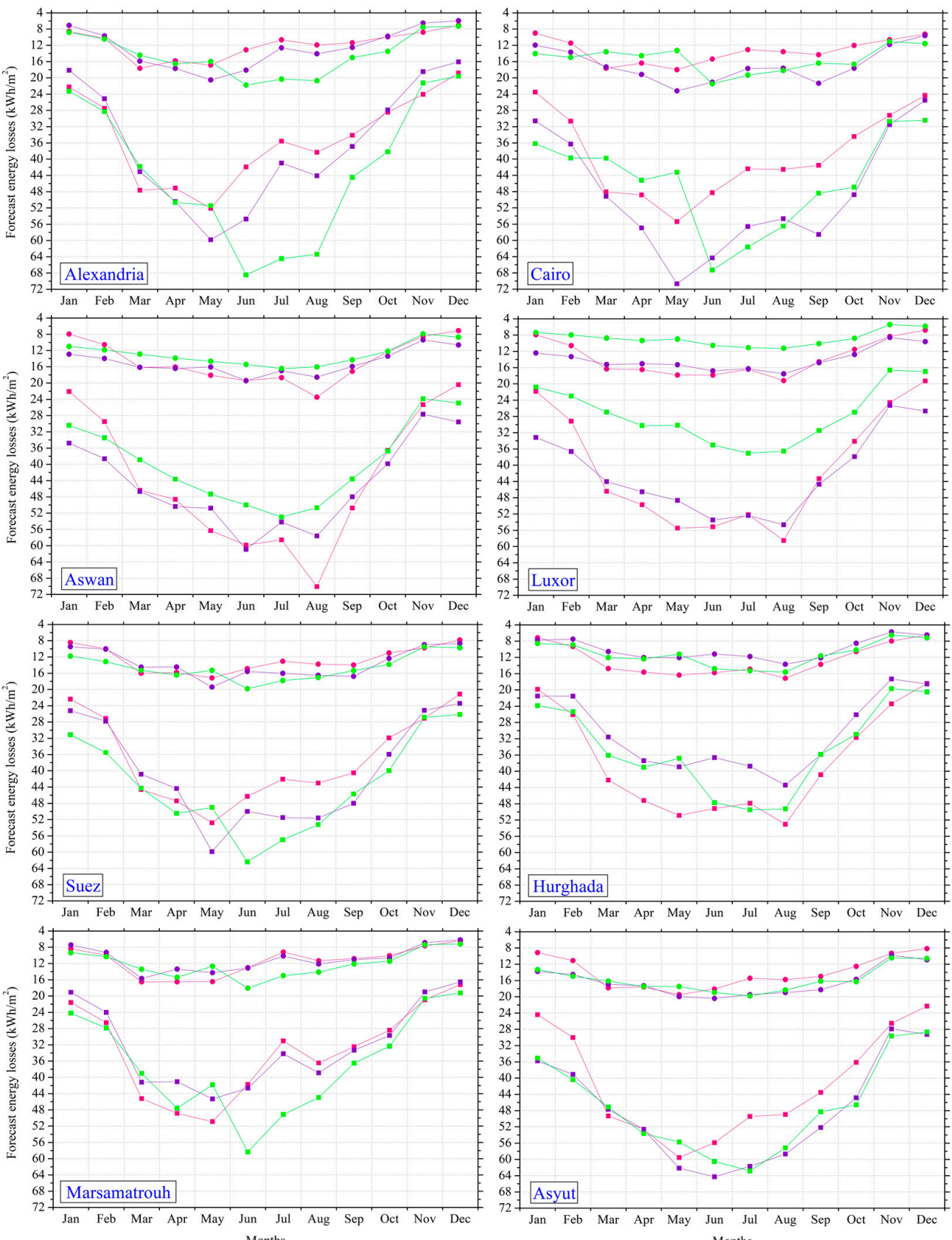

--CAMS DNI $\quad-$ CAMS GHI $\quad-$ - PERS DNI

- - PERS GHI - - CLIM DNI

CLIM GHI

Figure 7. Monthly mean forecast solar energy losses in $\mathrm{kWh} / \mathrm{m}^{2}$ for the regions of ALE, CAI, SUE, HUR, ASW, LUX, MAR and ASY. The AOD forecasting techniques of CAMS, MODIS PERS and MODIS CLIM were applied as inputs to the SENSE producing the solar energy potential in terms of GHI (circles) and DNI (squares). The CAMS produces 1-day forecasts with 3 hour temporal resolution, the PERS uses the MODIS AOD values of the previous day for the 1-day forecast as persistent aerosol conditions and the CLIM uses the monthly mean MODIS AOD values as steady aerosol conditions for every single time step of the whole month. 
For more detail of the above differences, in Figure 8 we present the daily forecast solar energy losses in March to observe the analytical GHI and DNI losses of the $3 \mathrm{M} \& \mathrm{P}$ approaches at three representative locations in terms of latitude and aerosol sources (CAI, ASY and ASW) [19-22]. At this temporal resolution, the basic assumption of PERS forecasting technique emerges. We observe that after the appearance of high aerosol loads, this method is unable to detect sudden changes and hence losses the actual particulate matter impact on solar energy (e.g., ASY at $18 \mathrm{March}$ ). On the other hand, the CLIM approach gives a fairly constant result, ignoring all fluctuations of aerosol load. Therefore, CAMS varies more than CLIM and monitors the AOD and its impact on solar energy having to deal with its modelling nature and the subsequently indeterminacies [74].
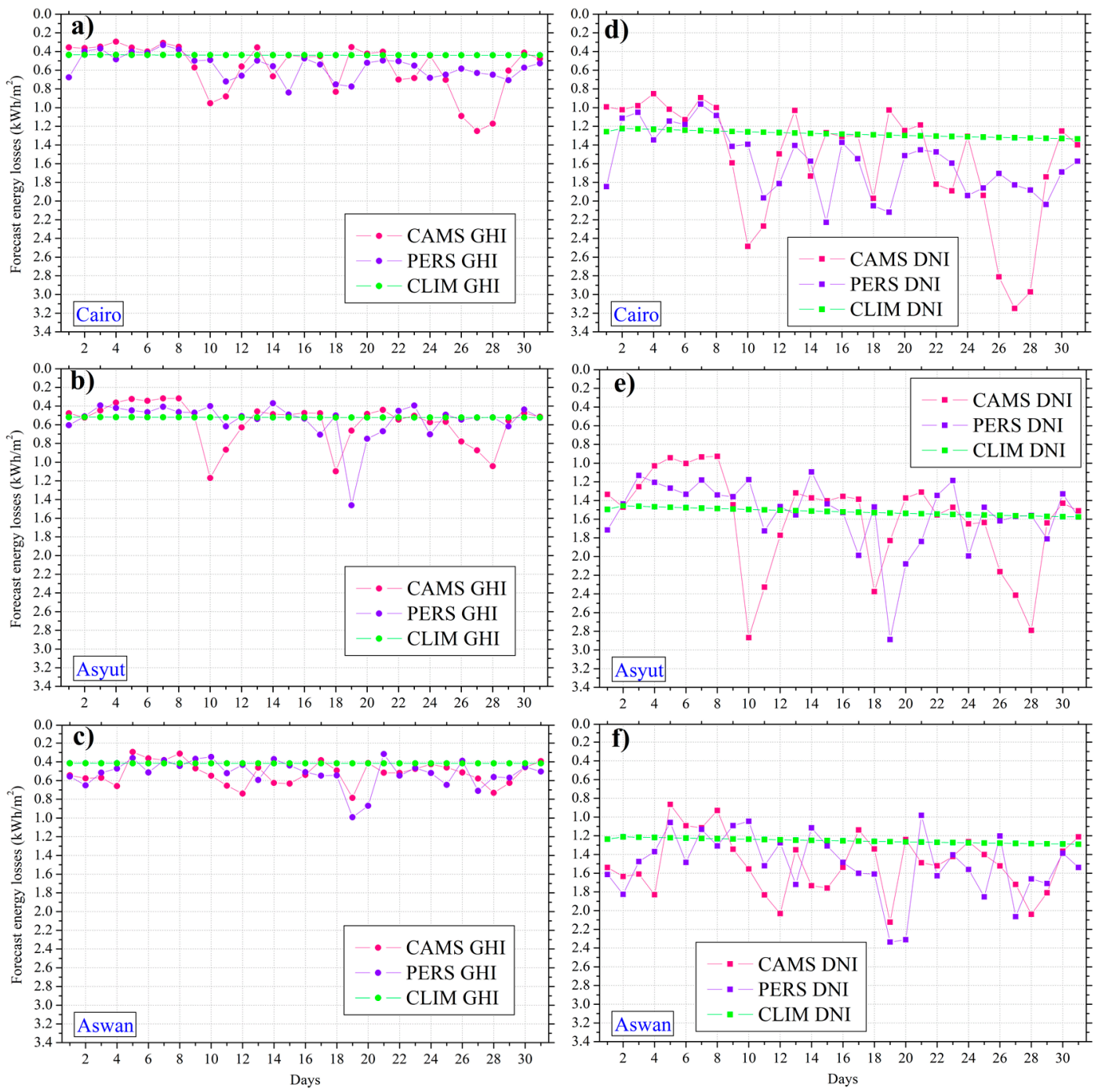

Figure 8. Daily mean forecast solar energy losses in $\mathrm{kWh} / \mathrm{m}^{2}$ for the regions of CAI (a,d), ASY (b,e) and ASW (c,f). The AOD forecasting techniques of CAMS, MODIS PERS and MODIS CLIM were applied as inputs to the SENSE producing the solar energy potential in terms of GHI $(\mathbf{a}-\mathbf{c})$ and DNI $(\mathbf{d}-\mathbf{f})$.

Finally, Figure 9 presents time series of simulated GHI in Aswan and DNI in Asyut, using CAMS AOD inputs to SENSE, in the form of contour plots for the past 3 years as well as direct comparison against the MODIS PERS and MODIS CLIM approaches. The percentage differences are larger near sunset and sunrise and during winter months (i.e., smaller absolute values) reaching 8-10\% for GHI and exceeding $20 \%$ for DNI, conditions that in both cases followed by low solar energy potential. The assessment of such differences can be a useful tool for future scientific or solar sector oriented 
business plan studies, as it will directly contribute to the particulate matter related uncertainties introduced to solar radiation and energy calculations and/or forecasts [81,82].
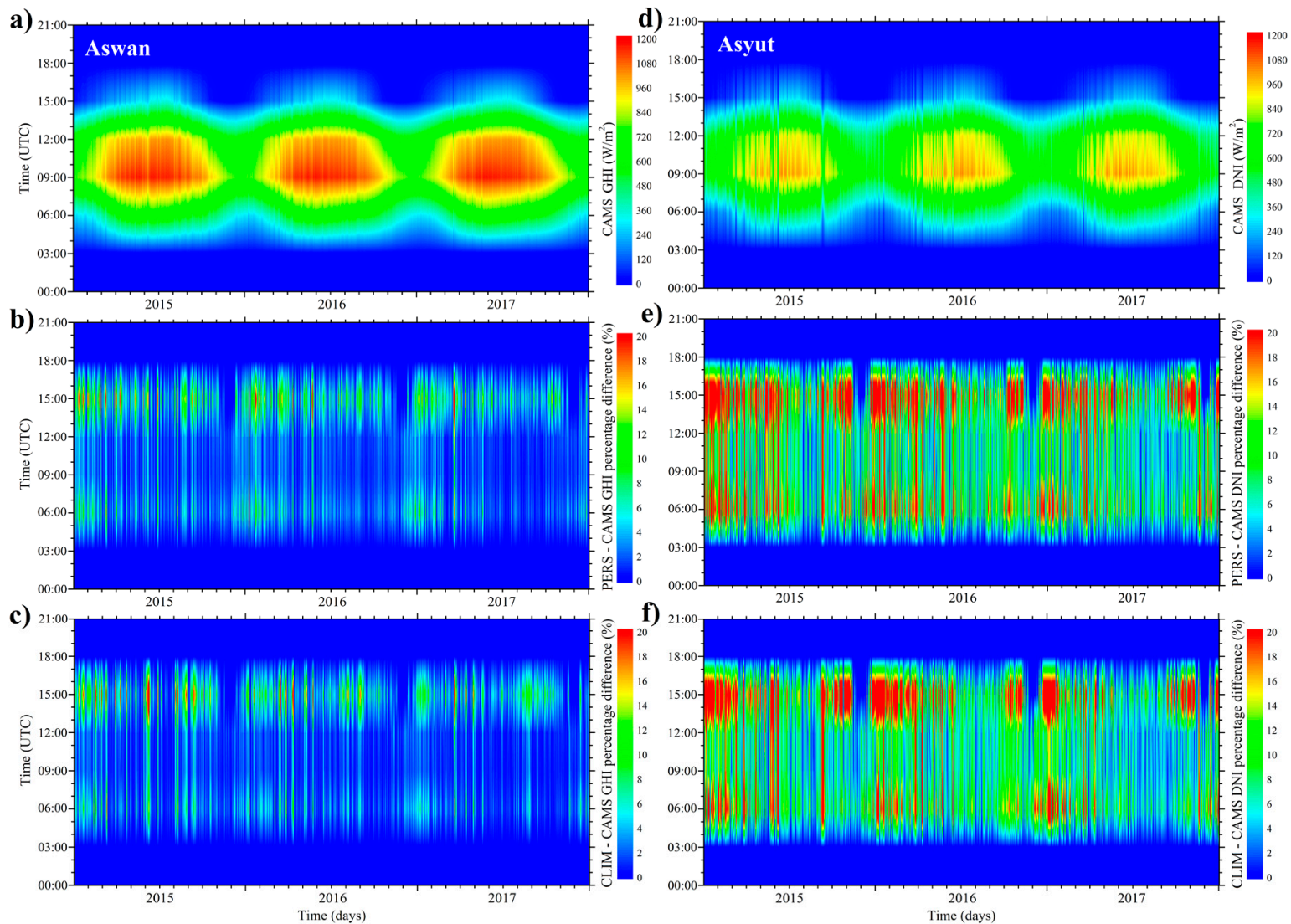

Figure 9. Contour plots of the GHI in Aswan $(\mathbf{a}-\mathbf{c})$ and DNI in Asyut $(\mathbf{d}-\mathbf{f})$ as simulated by SENSE using as AOD input the CAMS 1-day forecasts $(\mathbf{a}, \mathbf{f})$ and the percentage differences for GHI $(\mathbf{b}, \mathbf{c})$ and DNI $(\mathbf{e}, \mathbf{f})$ respectively as compared to the MODIS PERS and MODIS CLIM forecasting approaches for the period 2015-2017.

\subsection{Economic Impact}

Figure 10 presents the financial analysis results for the three specific locations of Figure 3 focusing on the hypothetical $10 \mathrm{MW}$ system. The economic and energy impact was quantified in terms of monthly means, total FL and solar energy potential, by using the CAMS forecasts, the SENSE and the information of Section 2.2.3. As we move to lower latitudes the PV energy potential as well as the annual revenue increase both, starting from $2620 \mathrm{kWh} / \mathrm{m}^{2}$ in CAI and reaching almost $2746 \mathrm{kWh} / \mathrm{m}^{2}$ in ASW with the revenue difference reaching almost 50,000 USD. The energy losses because of the total AOD are $161 \mathrm{kWh} / \mathrm{m}^{2}$ in CAI, 169 in ASY and 175 in ASW and the corresponding energy losses due to dust AOD are 64,88 and $107 \mathrm{kWh} / \mathrm{m}^{2}$ for CAI, ASY and ASW, respectively. In CSP systems, the annual aerosol and dust impact on the produced solar energy is much larger, since DNI is more affected than GHI [15]. Indicatively, in CAI the losses are $469 \mathrm{kWh} / \mathrm{m}^{2}$ under total AOD and 192 under dust presence, in ASY are 499 and $269 \mathrm{kWh} / \mathrm{m}^{2}$ and in ASW 524 and $329 \mathrm{kWh} / \mathrm{m}^{2}$. The economic impact for PV and CSP indicates that the annual FL in ASW are almost 70,000 and 200,000 USD respectively, because of the total AOD. We note that the annual revenues are of the order of 1,098,449 and 831,697 USD for PV and CSP plants respectively. In order to understand the relevance of these FL, the corresponding annual operating and maintenance costs of such a $10 \mathrm{MW}$ system in ASW are 221,000 and 340,000 USD for PV and CSP plants [83]. These costs include general site inspections, cleaning of the systems (mechanical maintenance and mirror cleaning), checking of various components (e.g., inverters, mounting/tracking, storage), local taxes, site security and administration costs [84]. Assessing also the effect of the CAMS 
AOD uncertainty mentioned in Section 2.1.1 on the SENSE solar energy output, we found in ASW a range of -3.6 to $1.8 \%$ (the minus symbol corresponds to an underestimation) for GHI and -12.3 to $5.7 \%$ for DNI. The magnitude of these percentages translates into annual uncertainty on the financial calculations of $-39,132$ to 18,816 USD for the 10 MW PV and $-101,052$ to 46,668 USD for the CSP.

a)

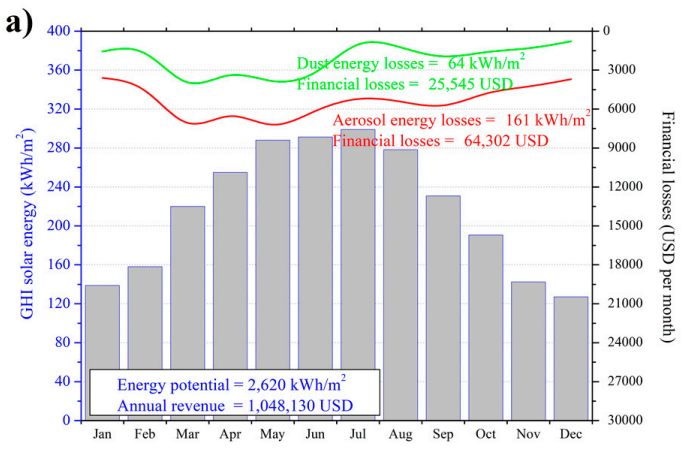

c)

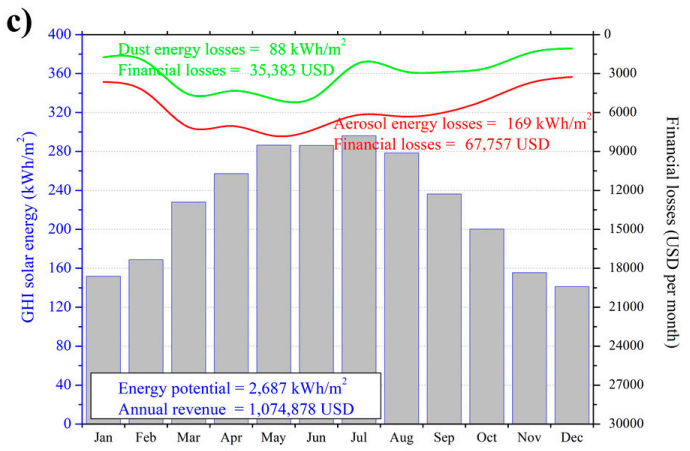

e)

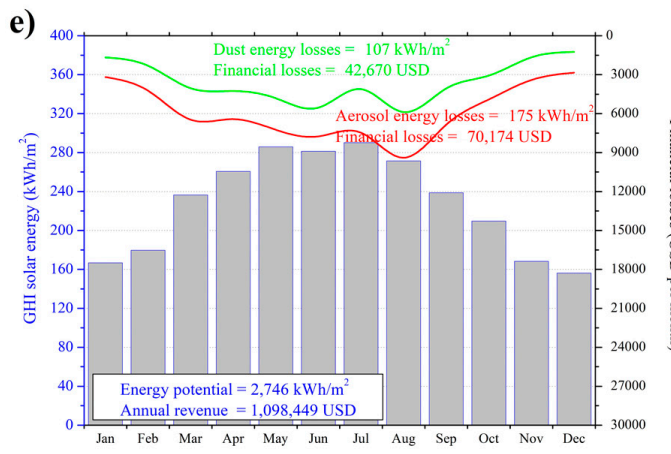

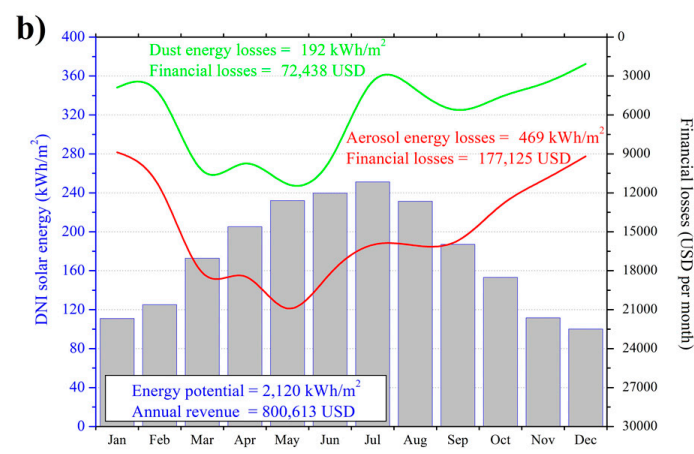

d)

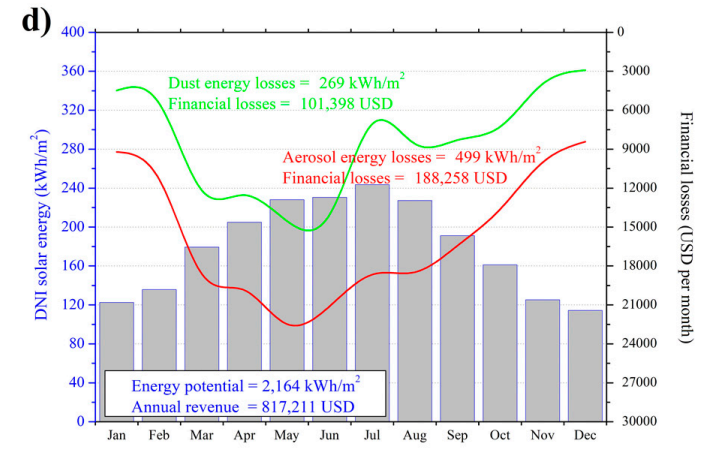

f)

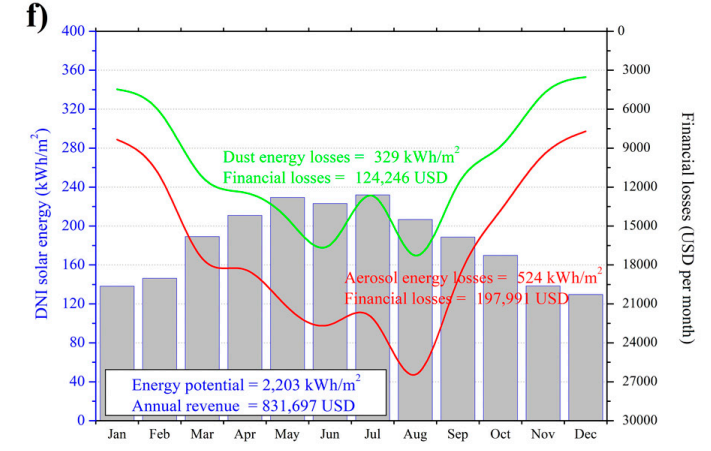

Figure 10. Financial analysis of the aerosol and dust impacts on the produced solar energy from PV $(\mathbf{a}, \mathbf{c}, \mathbf{e})$ and CSP $(\mathbf{b}, \mathbf{d}, \mathbf{f})$ installations with nominal power of 10MW in the regions of CAI $(\mathbf{a}, \mathbf{b}), \operatorname{ASY}(\mathbf{c}, \mathbf{d})$ and ASW $(\mathbf{e}, \mathbf{f})$. The impact was quantified in terms of monthly mean and total financial losses and solar energy potential.

Finally, Figure 11 represents the economic impact of forecasting solar energy under extreme dust event conditions. We studied the dust event of the 18th of March 2017 at the region of Asyut (inset map shown for the same date at 10:45 UTC from MODIS true colour imaging) as well as the previous and next day in order to identify the differences and the overall energy and financial impact. The AOD (a) exceeds 3 at the peak of the event as modelled by CAMS and reaches almost 3.5 on MODIS observations. Figure $11 \mathrm{~b}$ and $\mathrm{c}$ present the forecasted solar power and financial impact for the supposed 10 MW PV (b) and CSP (c) plants. The impact was quantified in terms of EP, DR and total FL as described in Section 2.2.3. The blue and red insets show the corresponding solar power and financial losses respectively, by using as input the MODIS observations, for reference purposes. The previous and next day of the dust event were also presented in order to quantify the magnitude of the extreme dust case on solar radiation and energy. 


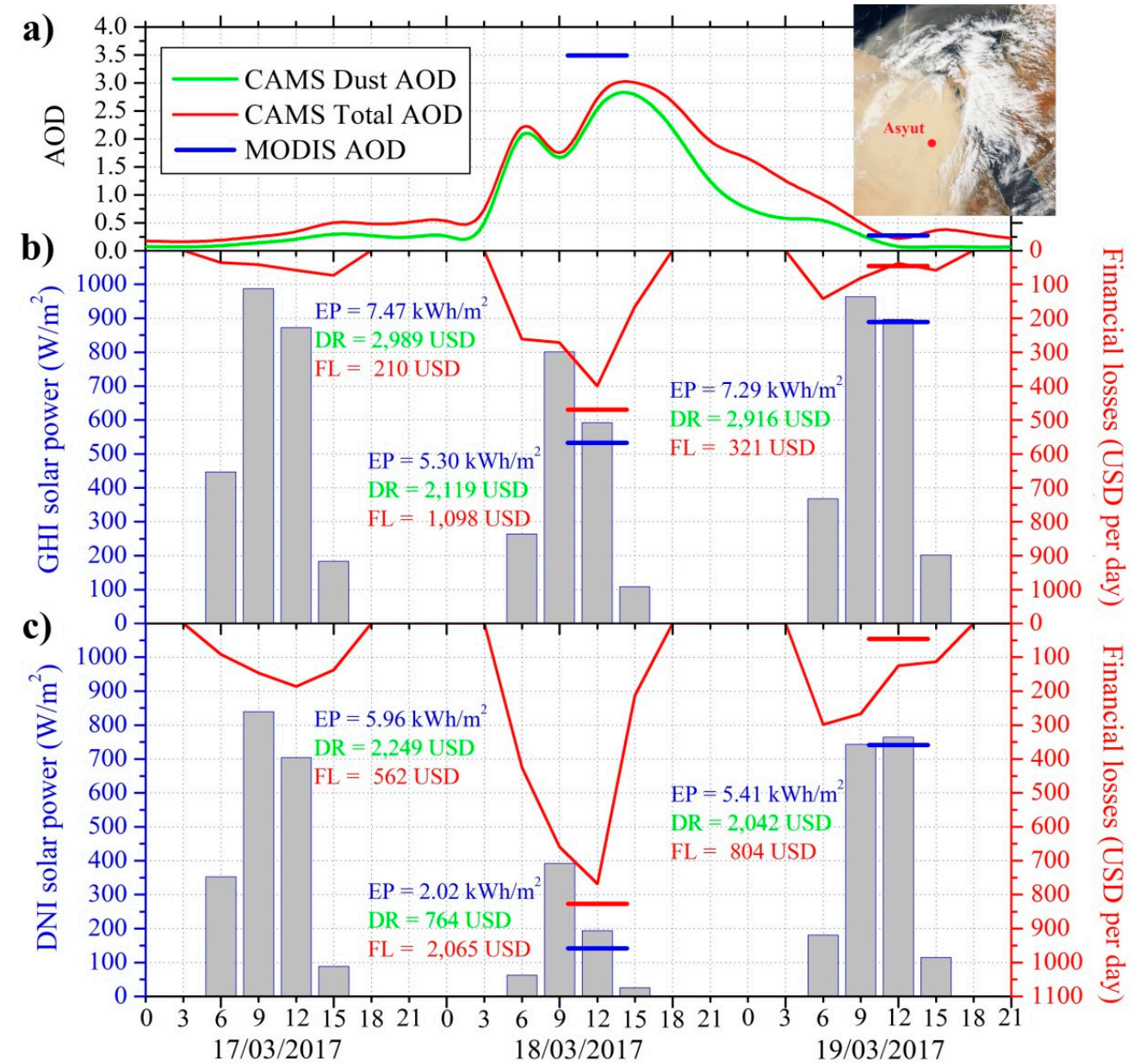

Figure 11. Temporal evolution and financial analysis of an extreme dust event impact (18 March 2017) on the CAMS AOD forecasted values (a) and on the produced solar energy from PV (b) and CSP (c) installations with nominal power of $10 \mathrm{MW}$ in the region of ASY. The impact was quantified in terms of EP, DR and total FL. The blue and red insets show the corresponding solar power and financial losses respectively, using as input the MODIS observations.

For the previous and next day, the daily energy production for PV systems was $7.47 \mathrm{kWh} / \mathrm{m}^{2}$ and 7.29 respectively, while at the peak of the dust event the EP was $5.3 \mathrm{kWh} / \mathrm{m}^{2}$. For the CSP case, the daily energy losses as compared to the previous and next day were almost $4 \mathrm{kWh} / \mathrm{m}^{2}$, meaning that for a $10 \mathrm{MW}$ system the daily FL are able to exceed the DR values [85]. This fact highlights also the impact of not having energy forecasts, since the FL represent the economic difference of the actual DR from the possible DR under aerosol-free conditions. So, the lack of forecasts means that the hypothetical aerosol-free DR during the 18th of March 2017 would have been estimated close to 2,829 USD (DR+FL) and therefore indicates the usefulness of the studied approach using the SENSE. The FL under such aerosol conditions for the 10 MW CSP system are 2,065 USD with the actual DR not exceeding the 764 USD. We note that all the above energy calculations and results were cross validated against real production data from the Egyptian energy market. Indicatively, a $10 \mathrm{MW}$ solar plant project in Aswan, is able to produce in a daily basis in March almost $7.43 \mathrm{kWh} / \mathrm{m}^{2}$ or $80 \mathrm{MWh}$ in total [86]. The corresponding values we simulated are 80.4, 57.1 and 78.5 MWh during 17, 18 and 19 March 2017, respectively. The lower EP during dust events is able to impact the local economy, since the required daily energy will be covered by the grid in higher prices (22 and 33 USD/MWh at off-peak and peak-time tariff) [87]. Therefore, the daily EP deficit on the 18th of March 2018 translates into an additional M\&P cost of 484-726 USD, as to purchase from the Egyptian grid the remaining $\approx 23 \mathrm{MWh}$. As a result, the ability to forecast the forthcoming dust events or in general the irregular 
high AOD differences, is translated to more efficient energy M\&P, minimizing the energy inadequacy by exploiting alternative energy sources or storing from the previous day energy into batteries for the case of PV systems or into melted salt as thermal energy for the case of CSP plants [76].

\section{Summary and Conclusions}

This study presented the estimation and forecasting techniques for the impact of particulate matter on solar energy in Egypt by exploiting the synergy of EO-based aerosol observations and forecasts from MODIS and CAMS with a state-of-the-art solar irradiance simulation system (SENSE). AOD was used as the main input parameter to SENSE and the aerosol effects on solar radiation revealed that the accuracy of estimated solar energy potential depends on the aerosol input data sources dealing with a trade-off between temporal frequency, availability of data and the overall M\&P usefulness and reliability.

We firstly described the modelling scheme and we proposed three different forecasting approaches (CAMS, PERS and CLIM) to investigate potential solutions for the quantification of the aerosol effects on solar energy production. The study was performed for the whole Egypt region as well as for eight specific locations with highly installed and planned solar energy capacity. The climatological analysis showed a dependence on seasonal variability with the highest attenuation to occur during spring and summer, reaching values of $8 \%$ for GHI and exceeding $20 \%$ in DNI for the majority of the Egyptian region. The evaluation of the PERS and CLIM forecasting solutions indicated alternative roadmaps for the $\mathrm{M} \& \mathrm{P}$, revealing a "shifted-reality" for the PERS, which is manageable and useful under steady atmospheric conditions but fails to predict upcoming large AOD values and differences. On the other hand, the CLIM is applicable only for large time-horizon averages (e.g., monthly means) keeping the background particulate matter information but missing the continuous variability which is a major M\&P requirement. Both solutions presented higher differences as compared to CAMS in winter months and at large SZA, conditions followed by minimum solar energy potential impact.

Overall, the combination of CAMS 1 day forecasts with the SENSE is a promising tool for the solar energy management community. We simulated a hypothetical energy financial scenario of a $10 \mathrm{MW}$ system under various latitudes, time-horizons and atmospheric conditions. In a climatological basis, such a system incurs the largest energy losses in the CSP form and in spring and summer months reaching almost $20 \%$ as compared to the annual energy production and the followed annual revenue. In the day-to-day and intra-day time-horizon monitoring scenario, we found that the FL are able to reach the $50 \%$ of the DR for the PV cases and overcome the DR by almost $270 \%$ for the CSP plants, which translates into daily energy losses of $4 \mathrm{kWh} / \mathrm{m}^{2}$, highlighting the holistic usefulness for M\&P market operations.

The findings show the potential of such EO-based techniques for solar energy applications and electricity grid TSO and DSO support services. As a result, the exploitation of EO data and solar energy management systems like the SENSE, are able to provide advanced solar energy related services, in support of large scale solar farm projects, grid operators, national and private electrical transmission and handling entities, so as to guarantee the uninterrupted energy flow and the power grid stability.

Author Contributions: P.G.K. and S.K. conceived and designed the research. P.G.K. analysed the data and wrote the manuscript. S.K. and H.E.-A revised the manuscript and adjusted the approach. M.T. and P.G.K. developed the initial NN. S.K. is the principal investigator and P.G.K. is the developer of the SENSE. C.K. is the principal investigator of the GEO-Cradle project within which the SENSE was designed, developed and applied. A.G. and E.P. downloaded and processed the MODIS data. M.M.E.-K. provided the Egyptian energy market details and the determinant financial sizes.

Funding: This research was partly funded by the COST Action "InDust" under grant agreement CA16202, supported by COST (European Cooperation in Science and Technology) and more specifically the Short Term Scientific Mission project "Finding".

Acknowledgments: P.G.K., S.K., H.E.-A. and C.K. acknowledge the GEO-Cradle project which has received funding from the EU's Horizon 2020 research and innovation programme under grant agreement No 690133. A.G. acknowledges the Dust-Glass project funded form the EU's H2020 research and innovation programme under the Marie Sklodowska-Curie grant agreement No 749461. E.P. acknowledges support through the Stavros Niarchos 
Foundation. We acknowledge Mossad El-Metwally and Stefane Alfaro for establishing and maintaining the El Farafra Aeronet site used in this study.

Conflicts of Interest: The authors declare no conflict of interest.

\section{Abbreviations}

\begin{tabular}{|c|c|}
\hline $\mathrm{AE}$ & Angstrom Exponent \\
\hline AeroCom & Aerosol Compositions between Observations and Models \\
\hline $\mathrm{AOD}$ & Aerosol Optical Depth \\
\hline CAMS & Copernicus Atmosphere Monitoring Service \\
\hline CLIM & Climatology \\
\hline COT & Cloud Optical Thickness \\
\hline CSP & Concentrated Solar Power \\
\hline DB & Deep Blue \\
\hline DNI & Direct Normal Irradiance \\
\hline DR & Daily Revenue \\
\hline DSO & Distribution System Operator \\
\hline DT & Dark Target \\
\hline ECMWF & European Centre for Medium-Range Weather Forecasts \\
\hline $\mathrm{EO}$ & Earth Observation \\
\hline $\mathrm{EP}$ & Energy Production \\
\hline EU & European Union \\
\hline FL & Financial Losses \\
\hline GHI & Global Horizontal Irradiance \\
\hline LUT & Look Up Table \\
\hline M\&P & Management and Planning \\
\hline MACC & Monitoring Atmospheric Composition and Climate \\
\hline MODIS & Moderate resolution Imaging Spectroradiometer \\
\hline NN & Neural Network \\
\hline NREA & New and Renewable Energy Authority \\
\hline NWP & Numerical Weather Prediction \\
\hline PERS & Persistence \\
\hline PV & Photovoltaic \\
\hline QA & Quality Assurance \\
\hline $\mathrm{R}$ & Coefficient of Determination \\
\hline RTM & Radiative Transfer Model \\
\hline SD & Standard Deviation \\
\hline SENSE & Solar Energy Nowcasting SystEm \\
\hline SSA & Single Scattering Albedo \\
\hline SSR & Surface Solar Radiation \\
\hline SZA & Solar Zenith Angle \\
\hline TOC & Total Ozone Column \\
\hline $\mathrm{TSO}$ & Transmission System Operator \\
\hline WV & Columnar Water Vapor \\
\hline
\end{tabular}

\section{References}

1. Solangi, K.H.; Islam, M.R.; Saidur, R.; Rahim, N.A.; Fayaz, H. A review on Global Solar Energy Policy. Renew. Sustain. Energy Rev. 2011, 15, 2149-2163. [CrossRef]

2. REN21. Renewables Global Futures Report: Great Debates towards 100\% Renewable Energy 2017. Available online: http:/ / www.ren21.net/wp-content/uploads/2017/03/GFR-Full-Report-2017.pdf (accessed on 27 September 2018).

3. International Energy Agency (IEA). Renewables: Analysis and Forecasts to 2022; International Energy Agency: Paris, France, 2017. 
4. UN. Progress towards the Sustainable Development Goals, Report of the Secretary-General 2017. Available online: http:/ /www.un.org/ga/search/view_doc.asp?symbol=E/2017/66\&Lang=E (accessed on 12 October 2018).

5. Omran, M.A. Analysis of solar radiation over Egypt. Theor. Appl. Clim. 2000, 67, 225-240. [CrossRef]

6. El-Sobki, M.S. Electrical sector in Egypt between challenges and opportunities-Full scale program for renewable energy in Egypt. Presented at the World Future Energy Summit, Abu Dhabi, UAE, 27 January 2015; Available online: http:/ / www.mesia.com/wp-content/uploads/Sobki\%20-\%20NREA\%20-\%20AbuDhabiJanuary\%2020-2015.pdf (accessed on 12 October 2018).

7. Khalil, A.; Mubarak, A.; Kaseb, S. Road map for renewable energy research and development in Egypt. J. Adv. Res. 2010, 1, 29-38. [CrossRef]

8. International Renewable Energy Agency (IRENA). Renewable Energy Outlook: Egypt; International Renewable Energy Agency: Abu Dhabi, UAE, 2018; ISBN 978-92-9260-069-3.

9. Middle East Solar Industry Association (MESIA). Solar Outlook Report 2018. Available online: https:/ / www. mesia.com/wp-content/uploads/2018/03/MESIA-OUTLOOK-2018-Report-7March2018.pdf (accessed on 8 November 2018).

10. Nabat, P.; Somot, S.; Mallet, M.; Sevault, F.; Driouech, F.; Meloni, D.; Di Sarra, A.; Di Biagio, C.; Formenti, P.; Sicard, M.; et al. Dust aerosol radiative effects during summer 2012 simulated with a coupled regional aerosol-atmosphere-ocean model over the Mediterranean. Atmos. Chem. Phys. 2015, 15, 3303-3326. [CrossRef]

11. Khalil, S.A.; Shaffie, A.M. Evaluation of transposition models of solar irradiance over Egypt. Renew. Sustain. Energy Rev. 2016, 66, 105-119. [CrossRef]

12. Schroedter-Homscheidt, M.; Oumbe, A.; Benedetti, A.; Moncrette, J.J. Aerosols for concentrated solar electricity production forecasts: Requirement quantification and ECMWF/MACC aerosol forecast assessment. Bull. Am. Meteorol. Soc. 2013, 94, 903-914. [CrossRef]

13. Maghami, M.R.; Hizam, H.; Gomes, C.; Radzi, M.A.; Rezadad, I.; Hajighorbani, S. Power loss due to soiling on solar panel: A review. Renew. Sustain. Energy Rev. 2016, 59, 1307-1316. [CrossRef]

14. Rieger, D.; Steiner, A.; Bachmann, V.; Gasch, P.; Forstner, J.; Deetz, K.; Vogel, B.; Vogel, H. Impact of the 4 April 2014 Saharan dust outbreak on the photovoltaic power generation in Germany. Atmos. Chem. Phys. 2017, 17, 13391-13415. [CrossRef]

15. Kosmopoulos, P.G.; Kazadzis, S.; Taylor, M.; Athanasopoulou, E.; Speyer, O.; Raptis, P.I.; Marinou, E.; Proestakis, E.; Solomos, S.; Gerasopoulos, E.; et al. Dust impact on surface solar irradiance assessed with model simulations, satellite observations and ground-based measurements. Atmos. Meas. Tech. 2017, 10, 2435-2453. [CrossRef]

16. Neher, I.; Buchmann, T.; Crewell, S.; Evers-Dietze, B.; Pfeilsticker, K.; Pospichal, B.; Schirrmeister, C.; Meilinger, S. Impact of atmospheric aerosols on photovoltaic energy production Scenario for the Sahel zone. Energy Procedia 2017, 125, 170-179. [CrossRef]

17. El-Askary, H.; Sarkar, S.; Kafatos, M.; El-Gahzawi, T. A multi-sensor approach to dust storm monitoring over the Nile Delta. IEEE Trans. Geosc. Remote Sens. 2003, 41, 2386-2391. [CrossRef]

18. El-Askary, H.; Farouk, R.; Ichoku, C.; Kafatos, M. Transport of dust and anthropogenic aerosol across Alexandria, Egypt. Ann. Geophys. 2009, 27, 2869-2879. [CrossRef]

19. Prasad, A.K.; El-Askary, H.; Kafatos, M. High altitude dust transport over Nile Delta during biomass burning season. Environ. Pollut. 2010, 158, 3385-3391. [CrossRef] [PubMed]

20. Marey, H.S.; Gille, J.C.; El-Askary, H.; Shalaby, E.A.; El-Raey, M.E. Aerosol climatology over Nile Delta based on MODIS, MISR and OMI satellite data. Atmos. Chem. Phys. 2011, 11, 10637-10648. [CrossRef]

21. Cowie, S.M.; Knippertz, P.; Marsham, H. A climatology of dust emission events from northern Africa using long-term surface observations. Atmos. Chem. Phys. 2014, 14, 8579-8597. [CrossRef]

22. Shokr, M.; El-Tahan, M.; Ibrahim, A.; Steiner, A.; Gad, N. Long-term, high-resolution survey of atmospheric aerosols over Egypt with NASA's MODIS data. Remote. Sens. 2017, 9, 1027. [CrossRef]

23. IPCC. Climate Change: The Physical Science Basis; Contribution of Working Group I to the Fifth Assessment Report of the Intergovernmental Panel on Climate Change; Stocker, T.F., Qin, D., Plattner, G.K., Tignor, M., Allen, S.K., Boschung, J., Nauels, A., Xia, Y., Bex, V., Midgley, P.M., Eds.; Cambridge University Press: Cambridge, UK; New York, NY, USA, 2013. [CrossRef] 
24. World Meteorological Organization (WMO). Global Atmospheric Watch (GAW) Aerosol Measurement Procedures, Guidelines and Recommendations, 2nd ed.; GAW Report No. 227; World Meteorological Organization: Geneva, Switzerland, 2016.

25. Li, X.; Wagner, F.; Peng, W.; Yang, J.; Mauzerall, D.L. Reduction of solar photovoltaic resources due to air pollution in China. Proc. Natl. Acad. Sci. USA 2017, 2017, 11462. [CrossRef] [PubMed]

26. Gerard, H.; Puente, E.I.R.; Six, D. Coordination between transmission and distribution system operators in the electricity sector: A conceptual framework. Util. Policy 2018, 50, 40-48. [CrossRef]

27. Haywood, J.M.; Allan, R.P.; Culverwell, I.; Slingo, T.; Milton, S.; Edwards, J.; Clerbaux, N. Can desert dust explain the outgoing longwave radiation anomaly over the Sahara during July 2003? J. Geoph. Res. 2005, 110, D05105. [CrossRef]

28. Rodwell, M.J.; Jung, T. Understanding the local and global impacts of model physics changes: An aerosol example. Q. J. R. Meteorol. Soc. 2008, 134, 1479-1497. [CrossRef]

29. Benedetti, A.; Reid, J.S.; Knippertz, P.; Marsham, J.H.; Di Giuseppe, F.; Remy, S.; Basart, S.; Boucher, O.; Brooks, I.M.; Menut, L.; et al. Status and future of numerical atmospheric aerosol prediction with a focus on data requirements. Atmos. Chem. Phys. 2018, 18, 10615-10643. [CrossRef]

30. Takenaka, H.; Nakajima, T.Y. Estimation of solar radiation using a neural network based on radiative transfer. J. Geophys. Res. 2011, 116, D08215. [CrossRef]

31. Inman, R.H.; Pedro, H.T.C.; Coimbra, C.F.M. Solar forecasting methods for renewable energy integration. Prog. Energy Combust. Sci. 2013, 39, 535-576. [CrossRef]

32. Lefevre, M.; Oumbe, A.; Blanc, P.; Espinar, B.; Gschwind, B.; Qu, Z.; Wald, L.; Schroedter-Homscheidt, M.; Hoyer-Klick, C.; Arola, A.; et al. McClear: A new model estimating downwelling solar radiation at ground level in clear-sky conditions. Atmos. Meas. Tech. 2013, 6, 2403-2418. [CrossRef]

33. Kosmopoulos, P.G.; Kazadzis, S.; Lagouvardos, K.; Kotroni, V.; Bais, A. Solar energy prediction and verification using operational model forecasts and ground-based solar measurements. Energy 2015, 93, 1918-1930. [CrossRef]

34. Kosmopoulos, P.G.; Kazadzis, S.; Taylor, M.; Raptis, P.I.; Keramitsoglou, I.; Kiranoudis, C.; Bais, A.F. Assessment of the surface solar irradiance derived from real-time modelling techniques and verification with ground-based measurements. Atmos. Meas. Tech. 2018, 11, 907-924. [CrossRef]

35. Qu, Z.; Oumbe, A.; Blanc, P.; Espinar, B.; Gesell, G.; Gschwind, B.; Gschwind, B.; Kluser, L.; Lenevre, M.; Sabonet, L.; et al. Fast radiative transfer parameterisation for assessing the surface solar irradiance: The Heliosat-4 method. Energy Meteorol. 2017, 26, 33-57. [CrossRef]

36. Allen, R.J.; Norris, J.R.; Wild, M. Evaluation of multidecadal variability in CMIP5 surface solar radiation and inferred underestimation of aerosol direct effects over Europe, China, Japan, and India. J. Geophys. Res. Atmos. 2013, 118, 6311-6336. [CrossRef]

37. Ishii, T.; Otani, K.; Takashima, T.; Xue, Y. Solar spectral influence on the performance of photovoltaic (PV) modules under fine weather and cloudy weather conditions. Prog. Photovolt. Res. Appl. 2013, 21, 481-489. [CrossRef]

38. Dirnberger, D.; Blackburn, G.; Müller, B.; Reise, C. On the impact of solar spectral irradiance on the yield of different PV technologies. Sol. Energy Mater. Sol. Cells 2015, 132, 431-442. [CrossRef]

39. El-Metwally, M. Simple new methods to estimate global solar radiation based on meteorological data in Egypt. Atmos. Res. 2004, 69, 217-239. [CrossRef]

40. El-Metwally, M.; Alfaro, S.C.; Abdel Wahab, M.M.; Favez, O.; Mohamed, Z.; Chatenet, B. Aerosol properties and associated radiative effects over Cairo (Egypt). Atmos. Res. 2011, 99, 263-276. [CrossRef]

41. El-Metwally, M.; Alfaro, S.C. Correlation between meteorological conditions and aerosol characteristics at an East-Mediterranean coastal site. Atmos. Res. 2013, 132-133, 76-90. [CrossRef]

42. Eissa, Y.; Korany, M.; Aoun, Y.; Boraiy, M.; Abdel-Wahab, M.M.; Alfaro, S.C.; Blanc, P.; El-Metwally, M.; Ghedira, H.; Hungershoefer, K.; et al. Validation of the surface downwelling solar irradiance estimates of the HelioClim-3 database in Egypt. Remote. Sens. 2015, 7, 9269-9291. [CrossRef]

43. Dee, D.P.; Uppala, S. Variational bias correction of satellite radiance data in the ERA-Interim reanalysis. Q. J. R. Meteorol. Soc. 2009, 135, 1830-1841. [CrossRef]

44. Inness, A.; Baier, F.; Benedetti, A.; Bouarar, I.; Chabrillat, S.; Clark, H.; Clerbaux, C.; Coheur, P.; Engelen, R.J.; Errera, Q.; et al. The MACC reanalysis: An 8 yr data set of atmospheric composition. Atmos. Chem. Phys. 2013, 13, 4073-4109. [CrossRef] 
45. Penning de Vries, M.J.M.; Beirle, S.; Hormann, C.; Kaiser, J.W.; Stammes, P.; Tilstra, L.G.; Tuinder, O.N.E.; Wagner, T. A global aerosol classification algorithm incorporating multiple satellite data sets of aerosol and trace gas abundances. Atmos. Chem. Phys. 2015, 15, 10597-10618. [CrossRef]

46. Eskes, H.; Huijnen, V.; Arola, A.; Benedictow, A.; Blechschmidt, A.M.; Botek, E.; Boucher, O.; Bouarar, I.; Chabrillat, S.; Cuevas, E.; et al. Validation of reactive gases and aerosols in the MACC global analysis and forecast system. Geosci. Model Dev. 2015, 8, 3523-3543. [CrossRef]

47. Boucher, O.; Pham, M.; Venkataraman, C. Simulation of the Atmospheric Sulfur Cycle in the LMD GCM: Model Description, Model Evaluation, and Global and European Budgets; Note 23; Inst. Pierre-Simon Laplace: Paris, France, 2002.

48. Reddy, M.S.; Boucher, O.; Bellouin, N.; Schulz, M.; Balkanski, Y.; Dufresne, J.L.; Pham, M. Estimates of global multi-component aerosol optical depth and direct radiative perturbation in the Laboratoire de Météorologie Dynamique general circulation model. J. Geophys. Res. 2005, 110, D10S16. [CrossRef]

49. Huijnen, V.; Eskes, H.J.; Basart, S.; Benedictow, A.; Blechschmidt, A.M.; Chabrillat, S.; Christophe, Y.; Cuevas, E.; Flentje, H.; Jones, L.; et al. Validation Report of the CAMS Near-Real-Time Global Atmospheric Composition Service. System Evolution and Performance Statistics. Copernicus Atmosphere Monitoring Service (CAMS) Report 2015, CAMS84_1_D1.1_201512. Available online: https:/ /atmosphere.copernicus. eu/sites/default/files/repository/CAMS84_1_D1.1_201512_0.pdf (accessed on 8 November 2018).

50. Dentener, F.; Kinne, S.; Bond, T.; Boucher, O.; Cofala, J.; Generoso, S.; Ginoux, P.; Gong, S.; Hoelzemann, J.J.; Ito, A.; et al. Emissions of primary aerosol and precursor gases in the years 2000 and 1750 prescribed data-sets for AeroCom. Atmos. Chem. Phys. 2006, 6, 4321-4344. [CrossRef]

51. Guelle, W.; Schulz, M.; Balkanski, Y.; Dentener, F. Influence of the source formulation on modeling the atmospheric global distribution of the sea salt aerosol. J. Geophys. Res. 2001, 106, 27509-27524. [CrossRef]

52. Schulz, M.; de Leeuw, G.; Balkanski, Y. Sea-salt aerosol source functions and emissions. In Emission of Atmospheric Trace Compounds; Granier, C., Artaxo, P., Reeves, C.E., Eds.; Kluwer Acad.: Norwell, MA, USA, 2004; pp. 333-354.

53. Morcrette, J.J.; Beljaars, A.; Benedetti, A.; Jones, L.; Boucher, O. Sea-salt and dust aerosols in the ECMWF IFS model. Geophys. Res. Lett. 2008, 35, L24813. [CrossRef]

54. Levy, R.C.; Remer, L.A.; Dubovik, O. Global aerosol optical properties and application to Moderate Resolution Imaging Spectroradiometer aerosol retrieval over land. J. Geophys. Res. Atmos. 2007, 112, D13210. [CrossRef]

55. Levy, R.C.; Remer, L.A.; Kleidman, R.G.; Mattoo, S.; Ichoku, C.; Kahn, R.; Eck, T.F. Global evaluation of the Collection 5 MODIS dark-target aerosol products over land. Atmos. Chem. Phys. 2010, 10, 10399-10420. [CrossRef]

56. Remer, L.A.; Kaufman, Y.J.; Tanre, D.; Mattoo, S.; Chu, D.A.; Martins, J.V.; Li, R.R.; Ichoku, C.; Levy, R.C.; Kleidman, R.G.; et al. The MODIS aerosol algorithm, products, and validation. J. Atmos. Sci. 2005, 62, 947-973. [CrossRef]

57. Remer, L.A.; Kleidman, R.G.; Levy, R.C.; Kaufman, Y.J.; Tanré, D.; Mattoo, S.; Martins, J.V.; Ichoku, C.; Koren, I.; Yu, H.; et al. Global aerosol climatology from the MODIS satellite sensors. J. Geophys. Res. Atmos. 2008, 113, D14S07. [CrossRef]

58. Hsu, N.C.; Jeong, M.J.; Bettenhausen, C.; Sayer, A.M.; Hansell, R.; Seftor, C.S.; Huang, J.; Tsay, S.C. Enhanced Deep Blue aerosol retrieval algorithm: The second generation. J. Geophys. Res. 2013, 118, 9296-9315. [CrossRef]

59. Levy, R.C.; Mattoo, S.; Munchak, L.A.; Remer, L.A.; Sayer, A.M.; Patadia, F.; Hsu, N.C. The Collection 6 MODIS aerosol products over land and ocean. Atmos. Meas. Tech. 2013, 6, 2989-3034. [CrossRef]

60. Sayer, A.M.; Munchak, L.A.; Hsu, N.C.; Levy, R.C.; Bettenhausen, C.; Jeong, M.J. MODIS Collection 6 aerosol products: Comparison between Aqua's e-Deep Blue, Dark Target, and "merged" data sets, and usage recommendations. J. Geophys. Res. Atmos. 2014, 119, 13965-13989. [CrossRef]

61. Hubanks, P.A.; Platnick, S.; King, M.D.; Ridgway, B. MODIS Atmosphere L3 Gridded Product Algorithm Theoretical Basis Document \& Users Guide; ATBD Reference Number: ATBD-MOD-30; MODIS Atmosphere Documents 2016; Available online: https://modis-images.gsfc.nasa.gov/index.html or https://modisimages.gsfc.nasa.gov/_docs/L3_ATBD_C6.pdf (accessed on 22 October 2018).

62. Sayer, A.M.; Hsu, N.C.; Bettenhausen, C.; Jeong, M.J. Validation and uncertainty estimates for MODIS Collection 6 "Depp Blue" aerosol data. J. Geophys. Res. 2013, 118, 7864-7873. [CrossRef] 
63. Mayer, B.; Kylling, A. Technical note: The libRadtran software package for radiative transfer calculations-Description and examples of use. Atmos. Chem. Phys. 2005, 5, 1855-1877. [CrossRef]

64. Emde, C.; Buras-Schnell, R.; Kylling, A.; Mayer, B.; Gasteiger, J.; Hamann, U.; Kylling, J.; Richter, B.; Pause, C.; Dowling, T.; et al. The libRadtran software package for radiative transfer calculations (version 2.0.1). Geosci. Model Dev. 2016, 9, 1647-1672. [CrossRef]

65. Dahlback, A.; Stamnes, K. A new spherical model for computing the radiation field available for photolysis and heating at twilight. Planet Space Sci. 1991, 39, 671-683. [CrossRef]

66. Taylor, M.; Kosmopoulos, P.G.; Kazadzis, S.; Keramitsoglou, I.; Kiranoudis, C.T. Neural network radiative transfer solvers for the generation of high resolution solar irradiance spectra parameterized by cloud and aerosol parameters. J. Quant. Spectr. Radiat. Transf. 2015, 168, 176-192. [CrossRef]

67. Hornik, K.; Stinchcombe, M.; White, H. Multilayer Feedforward Networks Are Universal Approximators. Neural Netw. 1989, 2, 359-366. [CrossRef]

68. Taylor, M.; Kazadzis, S.; Tsekeri, A.; Gkikas, A.; Amiridis, V. Satellite retrieval of aerosol microphysical and optical parameters using neural networks: A new methodology applied to the Sahara desert dust peak. Atmos. Meas. Tech. 2014, 7, 3151-3175. [CrossRef]

69. Shettle, E.P. Models of aerosols, clouds and precipitation for atmospheric propagation studies. In Proceedings of the AGARD Conference 454 on Atmospheric Propagation in the UV, Visible, IR and MM-Region and Related System Aspects, Copenhagen, Denmark, 9-13 October 1989; Available online: http:/ /www.dtic.mil/ $\mathrm{dtic} / \mathrm{tr} /$ fulltext/u2/a221594.pdf (accessed on 8 November 2018).

70. Hess, M.; Koepke, P.; Schult, I. Optical Properties of Aerosols and Clouds: The Software Package OPAC. Bull. Am. Meteor. Soc. 1998, 79, 831-844. [CrossRef]

71. Kato, S.; Ackerman, T.; Mather, J.; Clothiaux, E. The k-distribution method and correlated-k approxiamation for shortwave radiative transfer model. J. Quant. Spectrosc. Radiat. Transf. 1999, 62, 109-121. [CrossRef]

72. Kinne, S.; Schulz, M.; Textor, C.; Guibert, S.; Balkanski, Y.; Bauer, S.E.; Berntsen, T.; Berglen, T.F.; Boucher, O.; Chin, M.; et al. An AeroCom initial assessment-Optical properties in aerosol component modules of global models. Atmos. Chem. Phys. 2006, 6, 1815-1834. [CrossRef]

73. Kumar, S.; Devara, P.C.S. Along-term study of aerosol modulation of atmospheric and surface solar heating over Pune, India. Tellus B Chem. Phys. Meteorol. 2012, 64, 18420. [CrossRef]

74. Eskes, H.J.; Douros, J.; Akritidis, D.; Antonakaki, T.; Blechschmidt, A.M.; Clark, H.; Gielen, C.; Hendrick, F.; Kapsomenakis, J.; Kartsios, S.; et al. Validation of CAMS Regional Services: Concentrations Above the Surface, Status Update for March-May 2017. Copernicus Atmosphere Monitoring Service (CAMS) Report 2017. Available online: https:/ /atmosphere.copernicus.eu/sites/default/files/2018-08/CAMS84_2015SC2_ D84.5.1.8_D84.6.1.3_2017MAM_v1.pdf (accessed on 12 October 2018).

75. PVGIS. Photovoltaic Geographical Information System. Available online: http://re.jrc.ec.europa.eu/pvgis/ (accessed on 12 October 2018).

76. Eck, M.; Hirsch, T.; Feldhoff, J.F.; Kretschmann, D.; Dersch, J.; Gavilan Morales, A.; Gonzales-Martinez, L.; Bachelier, C.; Platzer, W.; Riffelmann, K.J.; et al. Guidelines for CSP yield analysis-Optical losses of line focusing systems; definitions, sensitivity analysis and modeling approaches. Energy Procedia 2014, 49, 1318-1327. [CrossRef]

77. Ouali, H.A.L.; Merrouni, A.A.; Moussaoui, M.A.; Mezrhab, A. Electricity yield analysis of a 50 MW solar power plant under Moroccan climate. In Proceedings of the International Conference on Electrical and Information Technologies (ICEIT) 2015, Marrakech, Morocco, 25-27 March 2015. [CrossRef]

78. El-Metwally, M.; Alfaro, S.C.; Abdel Wahab, M.M.; Zakey, A.S.; Chatenet, B. Seasonal and inter-annual variability of the aerosol content in Cairo (Egypt) as deduced from the comparison of MODIS aerosol retrievals with direct AERONET measurements. Atmos. Res. 2010, 97, 14-25. [CrossRef]

79. Robaa, S.M. A study of solar radiation climate at Cairo urban area, Egypt and its environs. Int. J. Clim. 2006, 26, 1913-1928. [CrossRef]

80. Kohil, E.E.; Saleh, I.H.; Ghatass, Z.F. A study of atmospheric aerosol optical properties over Alexandria city-Egypt. J. Phys. Conf. Ser. 2017, 810, 012033. [CrossRef]

81. Bellouin, N.; Boucher, O.; Haywood, J.; Reddy, M.S. Global estimate of aerosol direct radiative forcing from satellite measurements. Nature 2005, 7071, 1138-1141. [CrossRef] [PubMed]

82. Lee, L.A.; Reddington, C.L.; Carslaw, K.S. On the relationship between aerosol model uncertainty and radiative forcing uncertainty. Proc. Natl. Acad. Sci. USA 2016, 113, 5820-5827. [CrossRef] [PubMed] 
83. IRENA. Renewable Power Generation Costs in 2014, Report 2015. Available online: http:/ /www.irena.org/ - / media/Files/IRENA/Agency/Publication/2015/IRENA_RE_Power_Costs_2014_report.pdf (accessed on 9 November 2018).

84. Haney, J.; Burstein, A. PV System Operations and Maintenance Fundamentals. Solar America Board for Codes and Standards Report 2013. Available online: http:/ / www.solarabcs.org/about/publications / reports/operations-maintenance/pdfs/SolarABCs-35-2013.pdf (accessed on 12 November 2018).

85. IRENA. Renewable Energy Integration in Power Grids 2015, IEA-ETSAP and IRENA Technology Brief E15. Available online: http:/ / www.irena.org/DocumentDownloads/Publications/IRENA-ETSAP_Tech_Brief_ Power_Grid_Integration_2015.pdf (accessed on 7 August 2018).

86. Evenflow SPRL. Business Plan for the Establishment, Operation and Exploitation of a Solar Farm: Aswan's Solar Plant Project, Report 2017. Available online: http:/ / solea.gr/wp-content/uploads /2018/03/AswanSolar-Plant-Business-Plan.pdf (accessed on 11 November 2018).

87. MOEE. Ministry of Electricity and Renewable Energy of Egypt. Electricity Pricelist 2017-2018. Available online: http:/ / www.moee.gov.eg/english_new/home.aspx (accessed on 10 November 2018).

(C) 2018 by the authors. Licensee MDPI, Basel, Switzerland. This article is an open access article distributed under the terms and conditions of the Creative Commons Attribution (CC BY) license (http:/ / creativecommons.org/licenses/by/4.0/). 